\title{
STATIC AND DYNAMIC COEFFICIENT MEASUREMENTS FOR A THRUST COLLAR USED IN AN INTEGRALLY GEARED COMPRESSOR
}

\author{
A Thesis \\ by \\ THOMAS CHANDLER KERR \\ Submitted to the Office of Graduate and Professional Studies of \\ Texas A\&M University \\ in partial fulfillment of the requirements for the degree of \\ MASTER OF SCIENCE
}

$\begin{array}{ll}\text { Chair of Committee, } & \text { Dara W. Childs } \\ \text { Committee Members, } & \begin{array}{l}\text { Luis San Andrés } \\ \text { Stefan Hurlebaus }\end{array} \\ \text { Head of Department, } & \text { Andreas Polycarpou }\end{array}$

December 17, 2017

Major Subject: Mechanical Engineering

Copyright 2017 Thomas Kerr 


\begin{abstract}
Test rigs that replicate the conditions for thrust collars (TCs) used in an integrally geared compressor (IGC) are scarce. The test rig described here is based on a typical IGC and is the first rig specifically designed to measure the dynamic reaction force coefficients of the lubricated area of the TC. The test rig uses low-speed and high-speed shafts with independently controlled speed and a pneumatically pressurized thrust disk to apply an axial load $\bar{F}_{z}$ to create the hydrodynamic wedge that balances the imposed axial load. The speed ratio between the low-speed shaft (LSS) and the pinion shaft is 11.67. The geometry of the shafts matches that of a typical IGC. Tests were conducted at pinion speeds of 5, 7.5, and $10 \mathrm{krpm}$ and $\bar{F}_{z}=200,300$, and $400 \mathrm{~N}$. The resulting range of applied pressures is smaller than those arising in practice.
\end{abstract}

The author conducts static tests by applying an incrementally-increasing $\bar{F}_{z}$ on the pinion shaft and measuring the relative displacement between the BG and the TC $\left(\bar{\Delta}_{z}\right)$. One test is conducted at each predetermined spin speed. Run-out on the TC as well as the BW obscures the data. Averaging works well to eliminate the effects of run-out. The author uses the averaged $\bar{F}_{z}$ and $\bar{\Delta}_{z}$ values to create a static, load/ relativedisplacement curve and the slope is the measured static stiffness coefficient $\left(\bar{k}_{z}\right)$.

The axial stiffness coefficient results are compared to predictions from a code based on a 2016 model due to Cable et. al. Their dynamic reaction-force model is

$$
F_{T C}=-k_{z} \Delta_{z}-c_{z} \dot{\Delta_{z}}
$$


where $F_{T C}$ is the reaction force of the TC, and $c_{Z}$ is the axial damping coefficient. The trends and the magnitudes of the measured $\bar{k}_{z}$ values and the predicted values from San Andres code for $k_{z}$ agree very well, especially for the $5 \mathrm{krpm}$ test case.

The author then conducts dynamic tests involving an applied impulse load to the TC shaft. One hundred impulses are conducted at each spin speed $(\omega), \bar{F}_{Z}$ test condition for averaging purposes. A one degree of freedom damped motion model uses $\Delta_{z}(t)$ measurements to determine the damped natural frequency $\left(\omega_{d}\right)$ and damping factor $(\zeta)$ for each test point. The thrust collar mass $m_{T C}$ and the measured $\zeta$ were then used to calculate $k_{z}$ and $c_{z}$. The $k_{z}$ values obtained in this fashion were consistently (and markedly) smaller than the static $\bar{k}_{z}$ values. Based on the results, the author uses the following model

$$
F_{T C}=-k_{z} \Delta_{z}-c_{z} \dot{\Delta}_{z}-m_{z} \ddot{\Delta}_{z}
$$

that includes the virtual-mass coefficient $\left(m_{z}\right)$. The Cable et al. model was based on the Reynolds equation and accordingly did not produce a virtual-mass term.

The $m_{z}$ term is calculated for each test point using $\bar{k}_{z}, \omega_{d}$, and $\zeta . m_{z}$ increases as a function $\omega$ and $\bar{F}_{z}$. It ranges from 0 to $19.5 \mathrm{~kg}$; the mass of the pinion shaft is $12.8 \mathrm{~kg}$. Both predictions and measurements show an increase in $c_{Z}$ with increasing $\bar{F}_{Z}$. The test rig produced damping coefficients that increased for increasing $\omega$, while the predicted values decreased. The magnitude of $c_{z}$ was lower than the predicted damping by a factor of $2-10$. 


\section{ACKNOWLEDGEMENTS}

I would like to thank Dr. Dara Childs for the opportunity to research through the Texas A\&M Turbomachinery Laboratory. I would also like to thank Mr. Stephen Phillips and Mr. Ray Matthews for their help. I would also like to thank Dr. San Andrés and Dr. Hurlebaus for taking the time to be on my committee.

Andrew Crandall provided a solid base for my research. Apart from creating the test rig, he also provided help and insight whenever I needed it. All the other students in the turbolab provided support. I would also like to thank my family.

Lastly, I would like to thank God, giving, as best as I can in all things, Him the glory. 


\section{CONTRIBUTORS AND FUNDING SOURCES}

This thesis was under the supervision of a committee including Professor Childs (advisor) and Professor San Andres of the Mechanical Engineering Department and Professor Hurlebaus from the Civil Department. Credit is given to Andrew Crandall for developing the test rig, and to Travis Cable for determining the test matrix. The other work was conducted by the author.

Thanks are due to professor Childs for funding this project. Samsung Techwin also provided the funding necessary for building the test rig. 


\section{NOMENCLATURE}

$c_{Z} \quad$ Thrust collar lubricant film axial viscous damping

$[\mathrm{FT} / \mathrm{L}]$ coefficient

$\bar{F}_{Z} \quad$ Applied average axial resultant static force on TC from

$[\mathrm{F}]$ static loader

$F_{T C} \quad$ Thrust collar axial reaction force

$h \quad$ Film thickness

$k_{Z} \quad$ Dynamic thrust collar lubricant film axial stiffness coefficient

$\bar{k}_{Z} \quad$ Axial stiffness coefficient calculated from static loaddeflection tests

$N \quad$ Gear ratio

$[-]$

p Hydrodynamic pressure

$P_{T C} \quad$ Applied average unit-load on TC from static loader

$\alpha \quad$ TC taper angle

$\beta_{x}, \beta_{y}$, Angular misalignments of $\mathrm{BG}$ about $\mathrm{x}$ and $\mathrm{y}$-axis

$\mathrm{B}_{\mathrm{x}}, \mathrm{B}_{y} \quad$ Angular misalignments of $\mathrm{TC}$ about $\mathrm{x}$ and $\mathrm{y}$-axis

$\Delta_{B W} \quad$ Axial displacement of the BW

$\Delta_{T C} \quad$ Axial displacement of the TC

$\Delta z \quad$ Axial displacement of the TC relative to the BG

$\rho \quad$ Lubricant density

$\eta \quad$ Lubricant dynamic viscosity

$\left[\mathrm{FT} / \mathrm{L}^{2}\right]$

$\omega \quad$ HSS spin speed

\section{Subscripts}

$B G \quad$ Bull gear, applicable to a production integrally geared compressor.

HSS High speed shaft 
LSS Low speed shaft

TC Thrust collar

\section{Acronyms}

$B G \quad$ Bull gear, applicable to a production integrally geared compressor.

$B W \quad$ Bull wheel, applicable to the thrust collar test facility

EHD Elastohydrodynamic

$I G C$ Integrally geared compressor

TC Thrust collar

TPTB Tilting pad thrust bearing

$D E \quad$ Drive end

NDE Non-drive end 


\section{TABLE OF CONTENTS}

Page

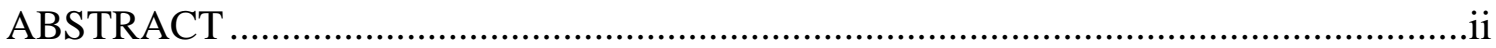

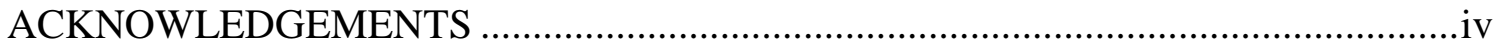

CONTRIBUTORS AND FUNDING SOURCES.......................................................

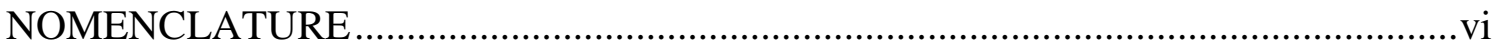

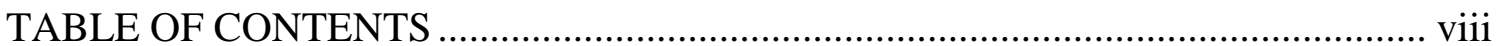

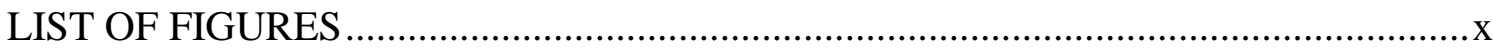

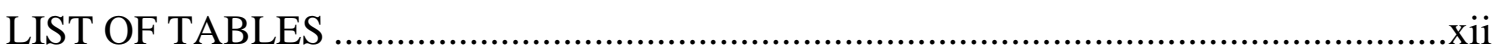

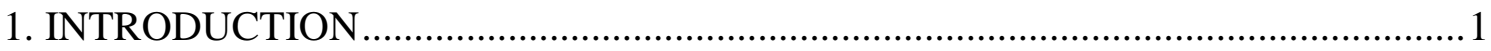

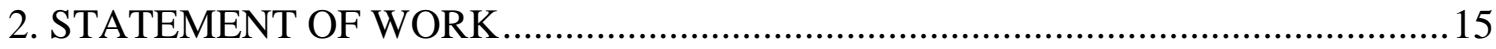

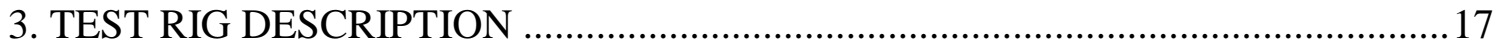

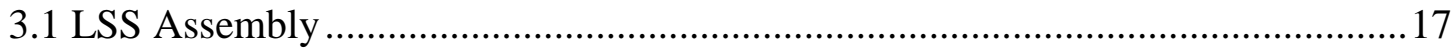

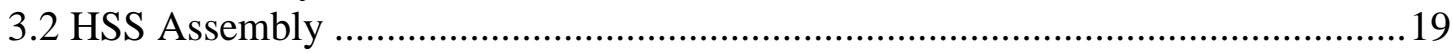

3.3 Impact Hammer ......................................................................................22

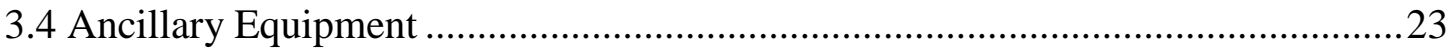

3.5 Additional Instrumentation and Data Acquisition ...............................................24

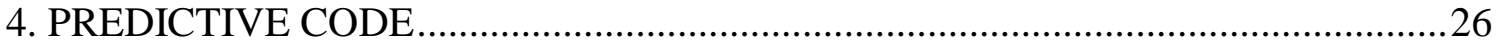

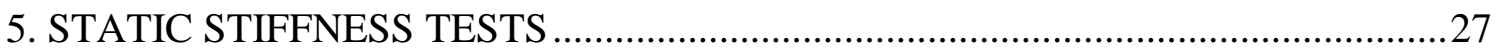

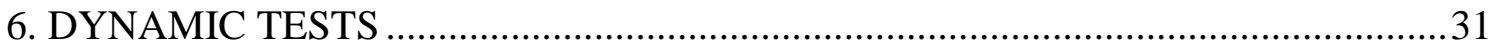

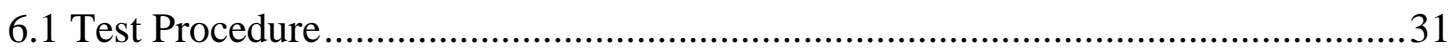

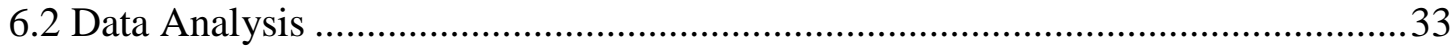

6.3 Limitations on 1 Degree of Freedom Assumption ....................................................37

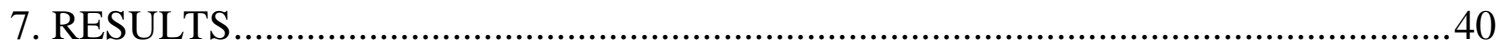

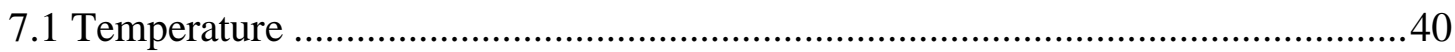

viii 
7.2 Damping Coefficients .....

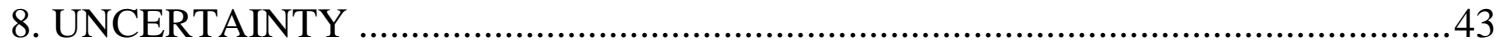

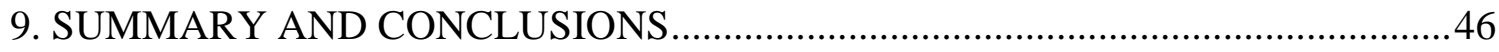

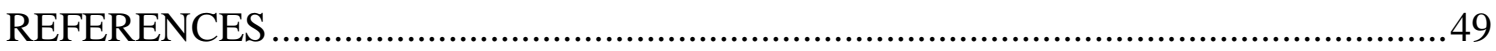

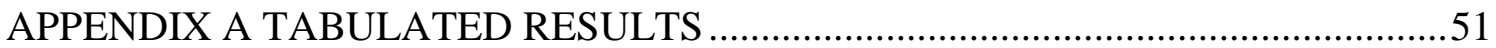




\section{LIST OF FIGURES}

Page

Figure 1. Cut-view of a two stage, single pinion IGC, reproduced from [1] .................. 1

Figure 2. Side view of a tilting-pad, thrust bearing [2] ...........................................

Figure 3. Lubricated area of a TC and BG interaction, adapted from [1]......................

Figure 4. Clearances for TC and thrust bearing in IGC. [3] ........................................

Figure 5. Load capacity based on taper angle (a) and minimum film thickness (b) [6]....6

Figure 6. Test rig designed by Parkins and Rudd [11] ..........................................

Figure 7. Computed and experimental data for central (left) and minimum (right) film

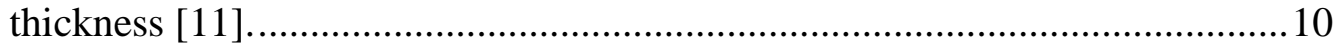

Figure 8. Lubricated zone for TC and BG line describing the geometries [5]...............12

Figure 9. TC with (a) no static misalignment and BG with (b) angular misalignment about $x$ axis, and (c) angular misalignment about the $y$ axis [5] ....................13

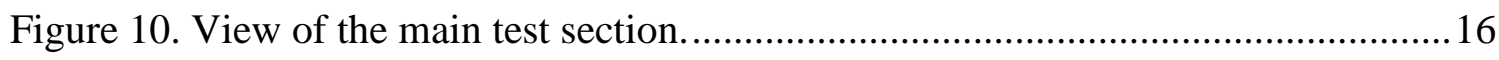

Figure 11. Low speed shaft. All dimensions are in $[\mathrm{mm}]$ in................................... 18

Figure 12. Schematic of the BW attached to the LSS. All dimensions are in [mm] (in). 19

Figure 13. HSS assembly, includes the TC. All dimensions are in [mm] (in.)..............20

Figure 14. Cross-section view of the pneumatic loader. ............................................21

Figure 15. Top view showing the position of all relevant sensors................................24

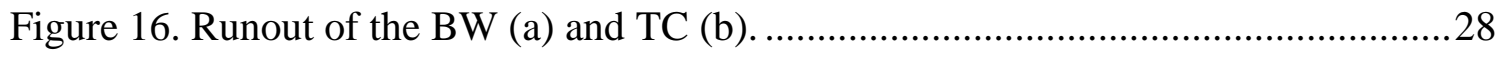

Figure 17. Axial force versus axial displacement of lubricated area ..........................29

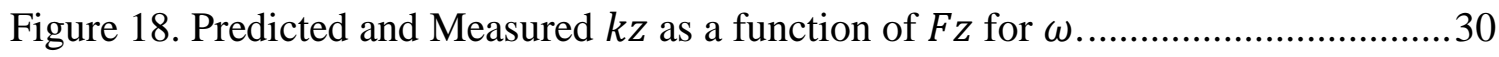

Figure 19. (a) TC axial displacement $\triangle T C$ (from 1"), and (b) BW axial displacement $\triangle B W$ (from $1^{*}$ ) for a single impact. 
Figure 20. (a) $(\triangle T C)$ and (b) ( $\triangle B W)$ measurements averaged over 100 impacts at

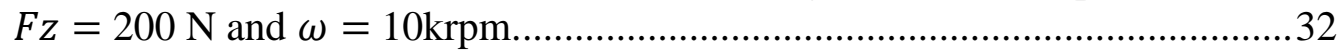

Figure 21. Model for axial vibration of the TC...............................................................33

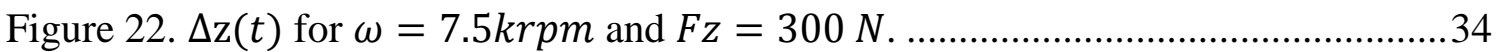

Figure 23. Measured static and dynamic stiffness as a function of $\omega \ldots \ldots \ldots \ldots \ldots \ldots \ldots \ldots \ldots \ldots . . . . .36$

Figure 24. Relative displacement vs. frequency for $\mathrm{Fz}=200$ to $600 \mathrm{~N}$..........................38

Figure 25. Relative displacement for $F Z=300$ (a), 500 (b), 700 (c), and $900 \mathrm{~N}$ (d).....39

Figure 26. Temperature rise of the ISO VG 32 oil versus time for the TC......................40

Figure 27. Measured and predicted $c z$ versus $\omega$ for three $F z$ values..............................41

Figure 28. Virtual mass coefficient versus spin speed for three axial forces....................42

Figure 29. Four sets of averaged relative displacements, calculated at $7.5 \mathrm{krpm}$ and $300 \mathrm{n}$.

Figure 30. Measured $c z$ versus $\omega$ showing standard deviation......................................44

Figure 31. Measured $m z$ versus $\omega$ showing standard deviation......................................45 


\section{LIST OF TABLES}

Page

Table 1. TC predictive code inputs that match the test rig.......................................26

Table A.1. All stiffness and damping values for measured results along with standard

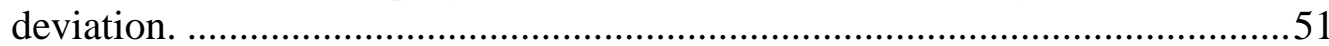

Table A.2. Static and dynamic stiffness values calculating virtual mass.......................51

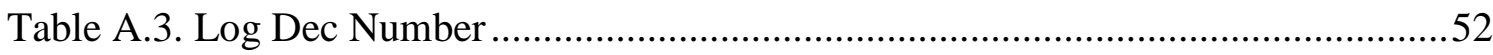




\section{INTRODUCTION}

Integrally geared compressors (IGCs) offer several advantages to conventional compressors including reduced footprint, increased efficiency, and ease of access [1]. The process gas will flow through multiple different compression stages. This allows the gas to be cooled between stages, increasing efficiency. The IGC, shown in Figure 1, operates using impellers on the ends of a single pinion shaft, driven by a bull gear (BG). The pinion can have impellers on both ends or be a single-impeller pinion.

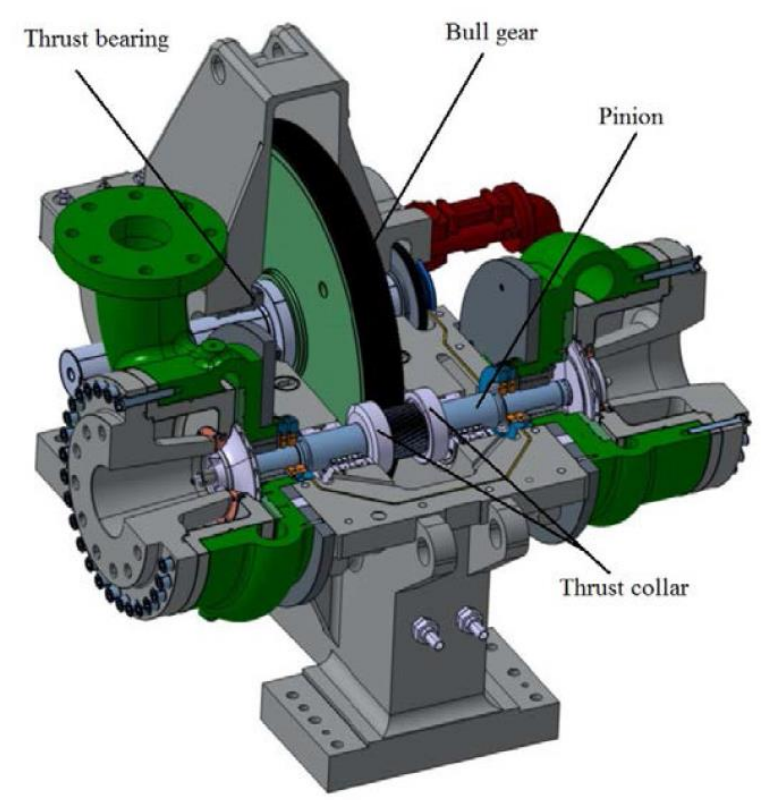

Figure 1. Cut-view of a two stage, single pinion IGC, reproduced from [1].

The helically geared connection between the pinion shaft and the bull gear can produce an axial load. This geared connection and the load produced by the hydrodynamic forces of the impellers are transmitted to the BG shaft using the thrust 
collar (TC) shown in Figure 1. These thrust loads are then distributed to a tilting pad thrust bearing attached to the BG shaft.

According to Cameron [2], the first fluid-film thrust bearing was patented in 1905 by George Michell. A typical thrust bearing uses a circular face that is broken into a number of wedge-shaped pads, typically three to twenty. All of the pads are held together within a carrier ring. In tilting pad bearings, the face of the wedge is free to tilt. Each pad will tilt, creating an inclined plane parallel to the surface that is spinning. A lubricant is either sprayed onto the pad, or is flooded into the housing. The incline between the shaft and the pad creates a hydrodynamic wedge that reacts axial forces.

Figure 2 displays a typical tilting-pad-thrust bearing (TPTB) pad. Cameron [2] conducted interferometry tests on a TPTB. He concluded that elastic deflection of the pad created the wedge that allowed hydrodynamic balancing to occur. Thrust bearings are an effective way to react axial forces, but because of their large wetted area, they consume large amounts of mechanical power.

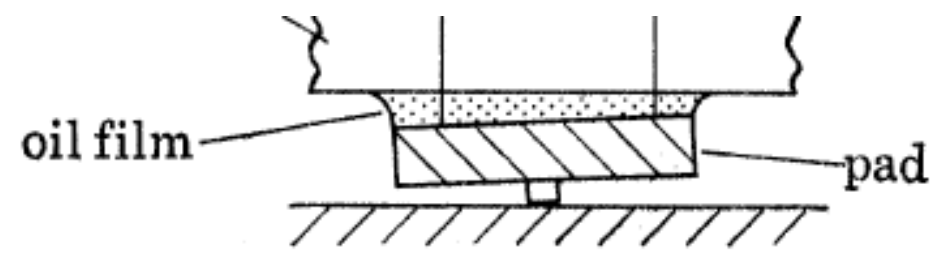

Figure 2. Side view of a tilting-pad, thrust bearing [2]

Thrust collars are similar to thrust bearings in reacting axial loads but operate differently. While rotation causes a lubricated wedge between a stationary bearing and a rotating shaft in a TPTB, a thrust collar uses tapered faces between two oppositely spinning shafts. The tapered angle $(\alpha)$ on the face of the BG, shown in Fig. 3, overlaps 
the similarly tapered face of the TC. As the area is lubricated, a converging hydrodynamic wedge transmits loads from the TC pinion to the BG shaft.

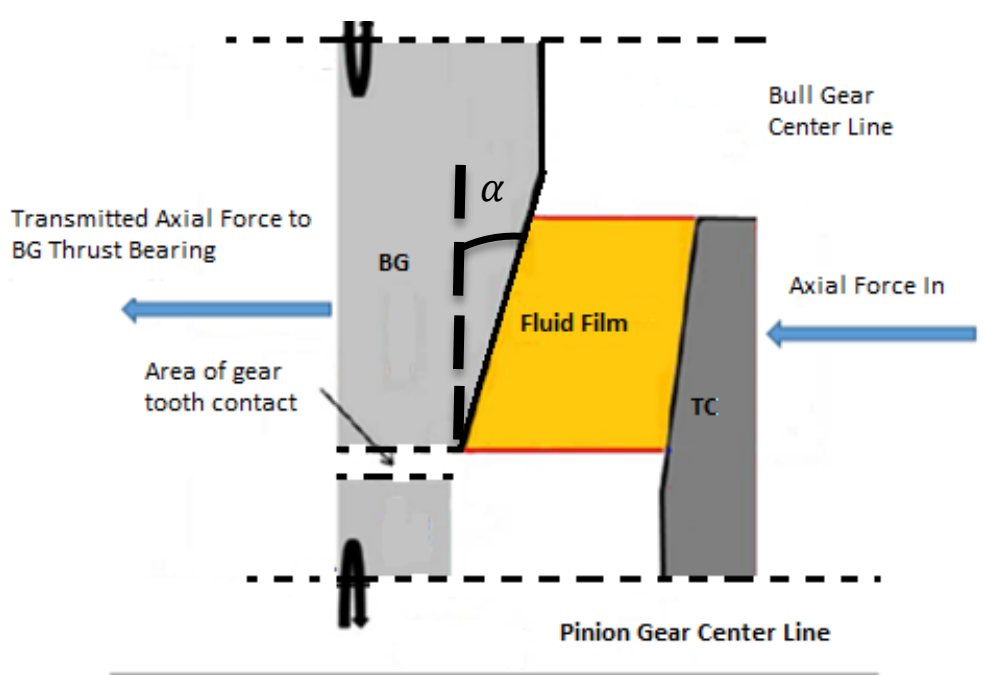

Figure 3. Lubricated area of a TC and BG interaction, adapted from [1].

IGC's provide the ideal application for TC's. Since the geared connection provides two oppositely spinning shafts, TC's can easily be implemented. The smaller lubricated area used in a TC reduces the mechanical power loss as compared to a thrust bearing [1].

Several papers list the advantages of using TCs in IGCs as opposed to a thrust bearing. Fingerhut et al. [3] describes the TC as an efficient way to balance forces created by the helical gears and the hydraulic forces. Figure 4 shows the different axial loads the TCs can transmit. TCs are an efficient way to balance all of the loads while only needing one thrust bearing. However, the increased efficiency comes at a cost of higher axial movement of the pinions. The axial clearance of the TC is stacked on the 
clearance of the BG-shaft thrust bearing, so that the pinion shaft will have greater axial displacements.

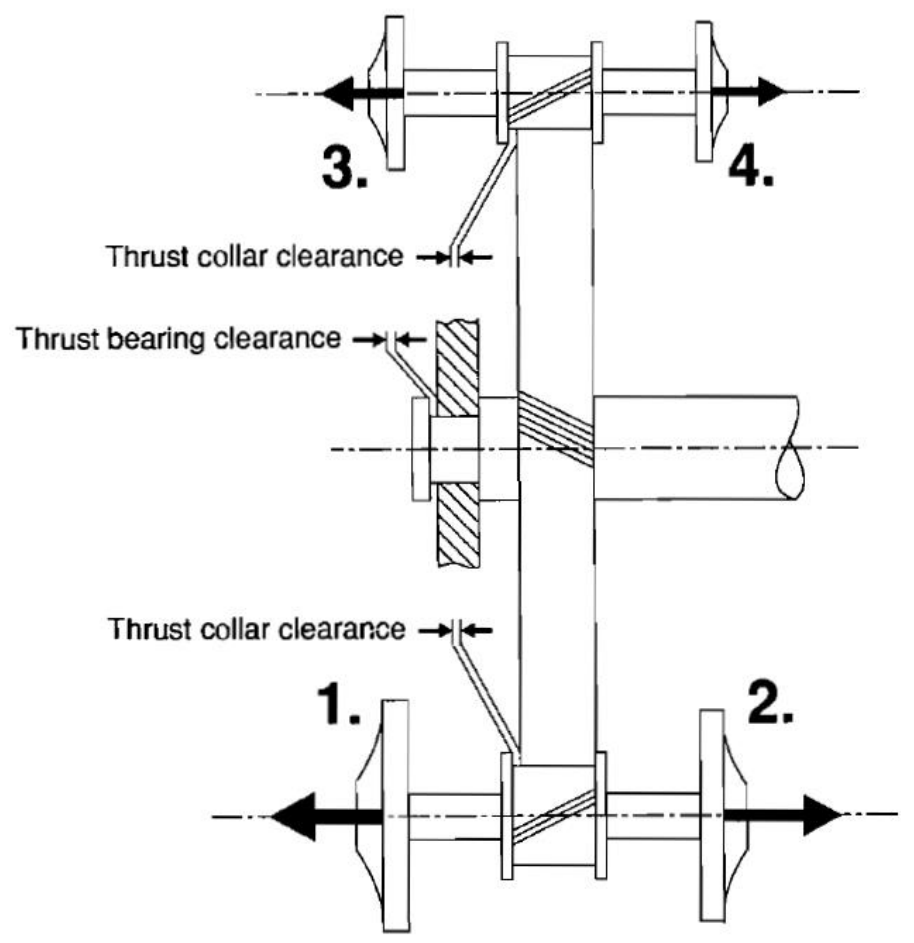

Figure 4. Clearances for TC and thrust bearing in IGC. [3]

The first approved patent for a TC in the United States was granted to Jakob Niederhauser, a Swiss inventor, in 1925 [4]. The principle advantage of the TC over a thrust bearing listed in the patent is the reduced cost. The paper indicates that the TC's primary use is for single helically-geared connections. The inventor indicates that for improved performance of the TC, a taper angle should be placed on either of the surfaces.

Although TC's have been around since the 1920's, one of their primary uses today is in IGCs. Other applications of the TC can be found in vertical pumps and 
passenger-vehicle transmissions [5]. TCs typically operate with machines using a geared connection. Because of the advantages of a geared connection in IGCs, and the axial loads produced by them, IGC manufacturers often employ TCs. The scope of the following review will focus on the use of thrust collars in IGCs.

The following parameters are of interest for TCs: load capacity, film thickness (h), pinion and BG geometry, speed of the BG $\left(\omega_{B G}\right)$, pinion speed $\left(\omega_{T C}\right)$, lubricant temperature $(T)$, axial reaction force $\left(F_{T C}\right)$, and type of lubricant. As discussed below, empirical and experimental tests have been published analyzing TC's based on these parameters.

The first tests for TCs were conducted by Sadykov and Shneerson [6] in 1968. The authors conduct tests on seven TC configurations. The tests were conducted to determine the ideal geometry of the pinion and BG, specifically the taper angle of the faces to maximize the load capacity. The tests vary $\alpha$, the TC connection to the pinion shaft, and the radius of the BG and TC. They recommend that $\alpha$ should only vary from 0.5 to 2 degrees. They determine that an $\alpha$ of at least 0.5 degrees is necessary to develop the hydrodynamic wedge. When the angle is above 2 degrees, the load capacity of the TC decreases. A difference in taper angle of $1 / 10$ to $2 / 15$ degrees between the TC and the BG can create scoring. They also stated that no direct method existed for predicting the load capacity at the time.

The first finite element analysis of a TC was presented by Langer [7] in 1982. Langer used the Reynolds equation to solve for load capacity and power loss for the TC system. Langer also includes the local flexibility of the BG and TC to present the first 
elastohydrodynamic (EHD) analysis of a lubricated thrust collar. He starts with the following dimensionless, steady-state, Reynolds equation,

$$
\frac{\partial}{\partial x}\left(\frac{h^{2}}{\eta} * \frac{\partial p}{\partial x}\right)+\frac{\partial}{\partial z}\left(\frac{h^{2}}{\eta} * \frac{\partial p}{\partial z}\right)=6 v \frac{\partial h}{\partial x}
$$

where $h$ is the film thickness, $p$ is the pressure distribution, $v$ is the effective speed which is the sum of the two velocities, and $\eta$ is the lubricant viscosity. The analysis shows that there is an ideal taper angle to achieve maximum load capacity. It also shows load capacity as a function of minimum film thickness. Both of these predictions are displayed in Fig. 5.

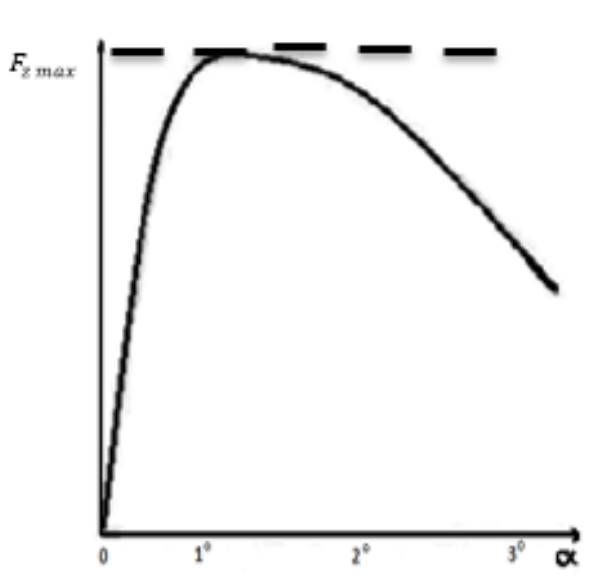

(a)

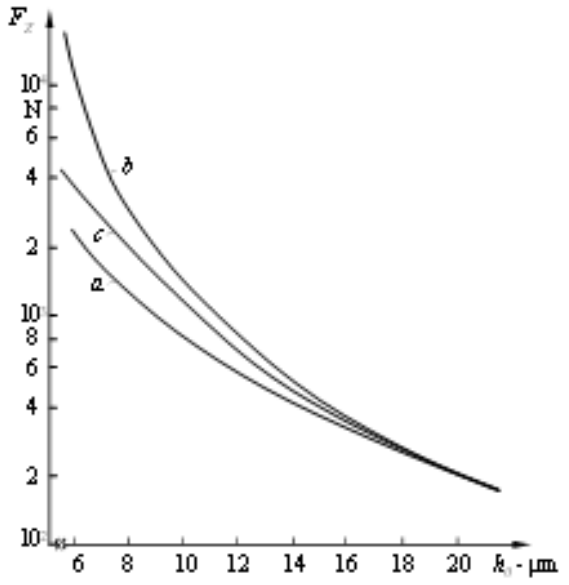

(b)

Figure 5. Load capacity based on taper angle (a) and minimum film thickness (b) [6].

Figure 5(a) shows an optimum taper angle for balancing axial load, located around one degree. The three plots in Fig. 5(b) show the minimum film thickness needed to balance an axial load. Curve $a$ is the most conservative and was calculated assuming 
there is no surface deflection. Curve $b$ also assumes there is no deflection, but does not assume constant pressure. Curve $c$ lies between the other curves, and accounts for the effect of pressure distribution and BG elastic deflection.

TCs are generally press fitted on to the pinion shaft and, at high loads, can slip axially, creating damage. Dietz and Mupende [8] furthered the slip analysis, determining the maximum deflection a pinion can undergo before it slips axially on the shaft. They conclude that a safety ring is advantageous for high axial loads.

After Langer publishes his results, Simon [9] presented another analysis including the thermal effects of the lubricant caused by friction between the two spinning faces. Simon uses the Reynolds, elasticity, and energy equations to create a full EHD analysis of the pressure, temperature, and shape of the fluid film between the BG and TC. Simon's energy equation is

$$
\begin{gathered}
\rho c_{p}\left(u \frac{\partial T}{\partial x}+v \frac{\partial T}{\partial y}+w \frac{\partial T}{\partial z}\right)-k_{o}\left(\frac{\partial T^{2}}{\partial x}+\frac{\partial T^{2}}{\partial y}+\frac{\partial T^{2}}{\partial z}\right) \\
=\alpha_{t} T\left(u \frac{\partial p}{\partial x}+v \frac{\partial p}{\partial y}\right)+\eta\left[\left(\frac{\partial u}{\partial z}\right)^{2}+\left(\frac{\partial v}{\partial z}\right)^{2}\right]
\end{gathered}
$$

where $u, v$, and $w$, all represent components of the lubricant velocity, $T$ is the film temperature, $\rho$ is the density, $c_{p}$ is the specific heat, and $p$ is the film pressure. His results showed that a higher viscosity oil will improve the load capacity of the TC. The other main conclusion was that higher axial loads can only be transferred at higher speeds. 
Yu and Sadeghi [10] conducted similar work investigating the thermohydrodynamic performance of thrust collars. Their analysis assumed that there was no deflection of the BG or TC. Using the modified Reynolds equation and the 3D thermal transport equation, they concluded that the TC's load-carrying capacity is reduced as lubricant temperature increases. They encourage a constant flow of freshly cooled lubricant to the TC.

Barragan et al. [11] paralleled the analysis of Langer by investigating the effects of density and viscosity as a function of pressure. While Langer's model determined the power loss and load capacity, Barragan's model predicted the minimum film thickness, an important parameter to prevent rubbing.

To determine the accuracy of Barragan's predictions, Parkins and Rudd [12] created a test rig to measure the film thickness as it varies with speed. They use a TC made of glass in conjunction with a metallurgical microscope and videography equipment to measure light interference fringes. A photo of their test rig is shown in Figure 6. 


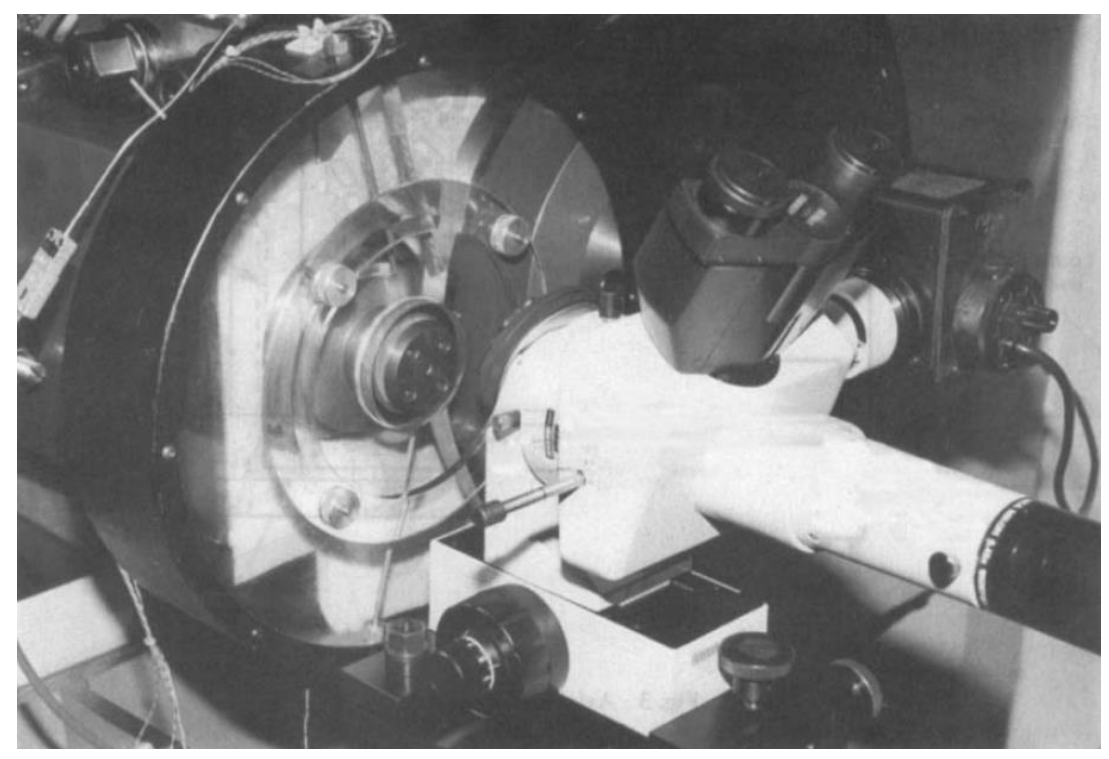

Figure 6. Test rig designed by Parkins and Rudd [11].

The test rig could deliver a $10 \mathrm{kN}$ maximum axial load and a pinion spin speed of 2,750 rpm. The glass TC can be seen in Figure 6, as well as the microscope necessary for viewing the lubricant. The film thickness is calculated from the light fringe data. They concluded that the predicted $h$ value agrees within 95\% confidence intervals with the experimental results.

Figure 7 shows their test results. The computed predictions are taken from Barragan et al.'s model. Parkins and Rudd define the central film thickness as the average thickness across the lubricated area. As shown, the measurement agrees well with the code for both the minimum film thickness and central film thickness. As spin speed increases, the film thickness will also increase. 

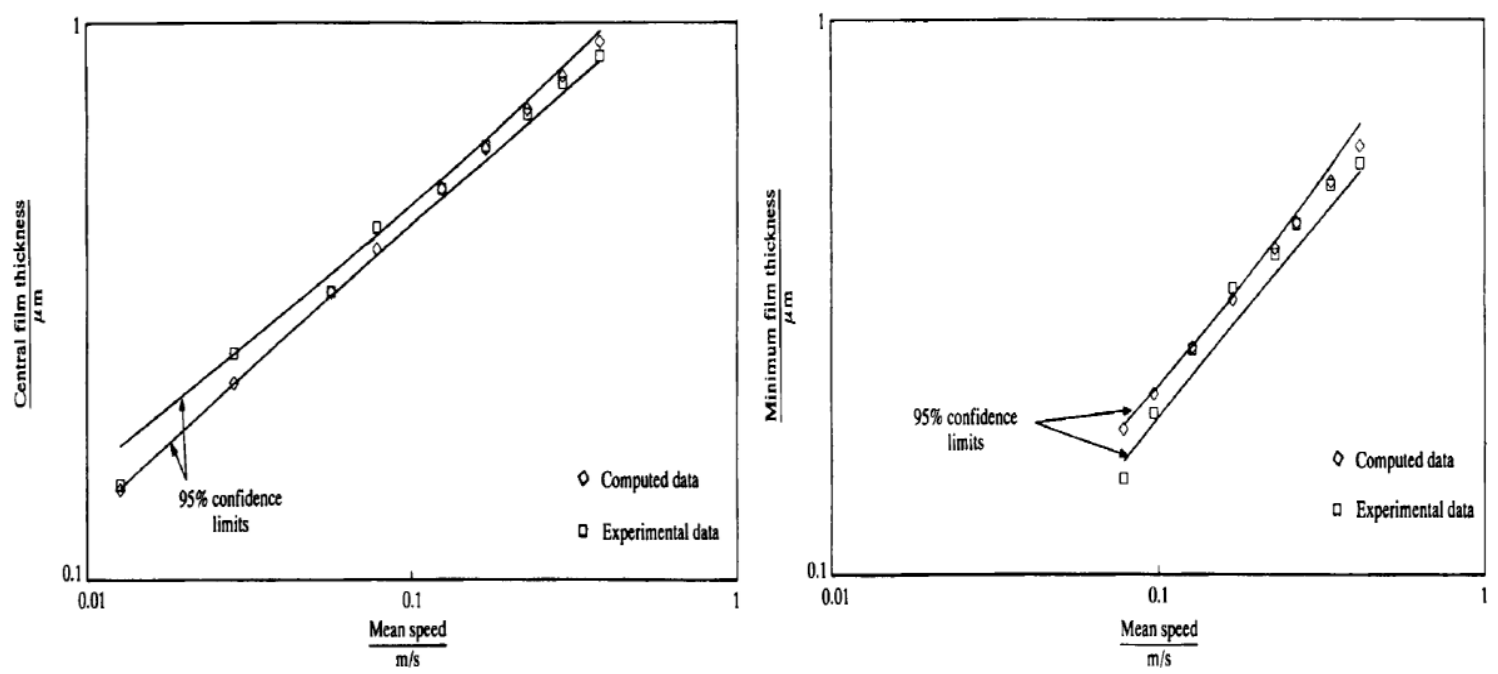

Figure 7. Computed and experimental data for central (left) and minimum (right) film thickness [11].

In 2006, Thoden [13] created a numerical code using Matlab to analyze the fluid film interaction. The code inputs are speed, axial force, and geometry of the TC and BG. Thoden accounts for the relative speed, the temperature influence, and the surface roughness. He uses EHD theory along with corrections for temperature, speed, and surface influence. The outputs are shown in graphical form displaying the relative speed which is the summation of the BG and TC speed divided by two, shear stress, and friction power. Most importantly, the code determines the minimum speed at which complete separation of the surfaces occurs.

To test his theory, Thoden [14] created a test rig, based largely on the machine created by Parkins and Rudd. No results are published, so it is impossible to tell the accuracy or effectiveness of Thoden's model. The test rig design allows for modifications to be made to the speed, axial force, and geometry (contact length, taper angle, and surface roughness). The primary focus of the tests was to determine if a 
certain set of test parameters create wear. This result determines the minimum speed required for hydrodynamic separation. A set of test parameters would be fixed, and the machine would be run. After the TC had run to steady state, the machine was stopped, and the TC face was inspected for wear.

Hess [15] conducted different tests using Thoden's test rig. While Thoden was testing different parameters to determine when wear on the thrust collars occurred, Hess uses the rig to determine when full hydrodynamic lift occurs. Full hydrodynamic lift is achieved when BG and TC do not contact each other. Hess uses the electrical resistance of the lubricant to determine when liftoff is achieved. He concluded, as expected, that an increase in speed was required to maintain lift while the axial force is increased. He also concluded that a modest $(0.5 \mathrm{~m} / \mathrm{s}$ at the surface $)$ spin speed is required to achieve lift.

In 2016, Cable et al. [5] present a solution for TCs using an isothermal, hydrodynamic finite element analysis. They use the Reynolds equation along with the energy transport equation to obtain a model describing the dynamic characteristics of the interaction. They assume that the $\mathrm{TC}$ and $\mathrm{BG}$ are rigid. This is the first study to predict the dynamic characteristics of a TC, specifically for use in an IGC. Their study takes into effect the elasticity of the BG and TC, as well as the lubricant heat transfer. The model also looks at the effect of misalignment of the BG, TC, or their respective shafts. All the presented predictions are normalized, but are representative of a TC in use of an IGC.

The full model includes a Reynolds equation for an incompressible fluid, and the film thickness between the TC and BG is characterized by 


$$
\begin{aligned}
h(r, \theta) & =h_{R_{1}}+\left(R_{1}-d+b\right) \tan \left(\phi_{B}\right)-\left(R_{1}-r\right) \tan \left(\phi_{T C}\right) \\
& +r \cos (\theta)\left\{\mathrm{B}_{y}-\beta_{\mathrm{y}}\right)+d \beta_{y}+r \sin (\theta)\left(\beta_{x}-\mathrm{B}_{x}\right)
\end{aligned}
$$

where $R_{1}, d, b, \phi_{B}, \phi_{T C}$, are all geometries of the TC-BG overlap area, and can be determined from Fig 8 .

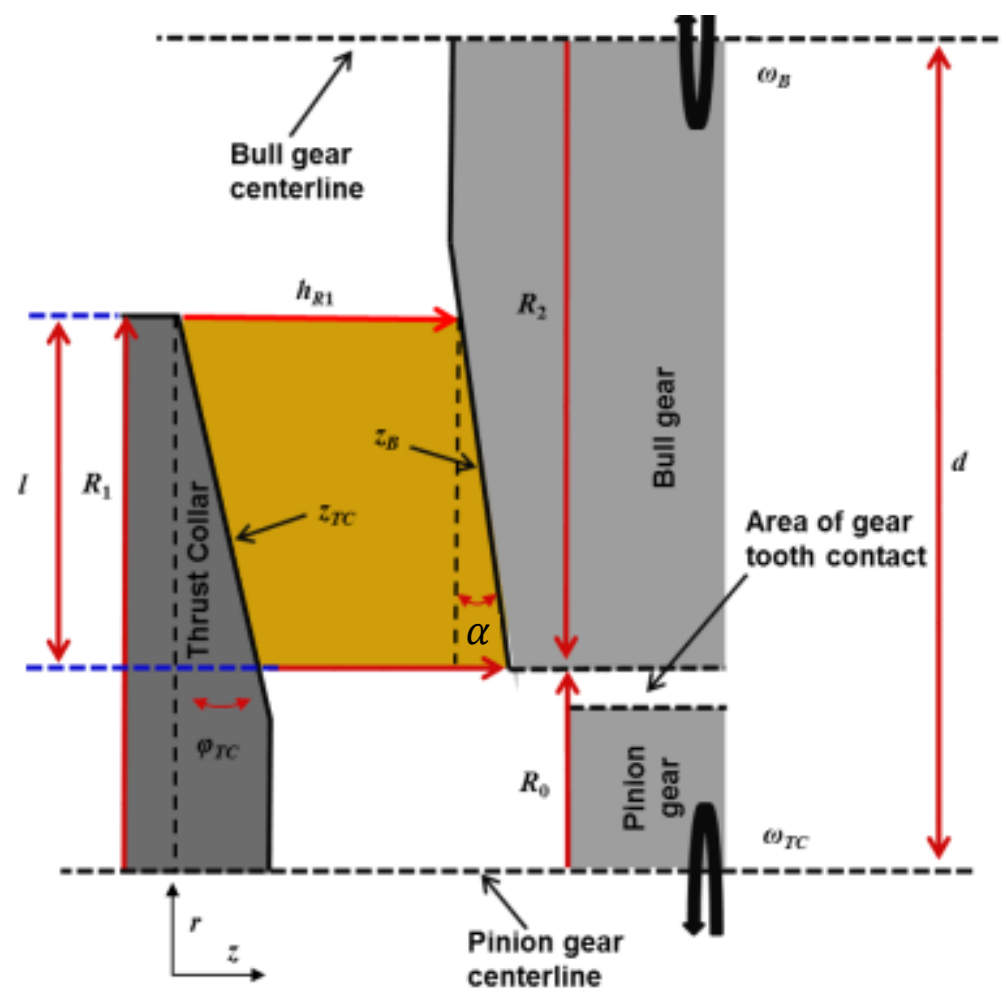

Figure 8. Lubricated zone for TC and BG line describing the geometries [5].

Figure 9 illustrates the small static-angular misalignments of the BG shown by $\beta_{x}, \beta_{y}$. The angular misalignments of the $\mathrm{TC}, \mathrm{B}_{x}$ and $\mathrm{B}_{y}$, are not shown in the figure. 


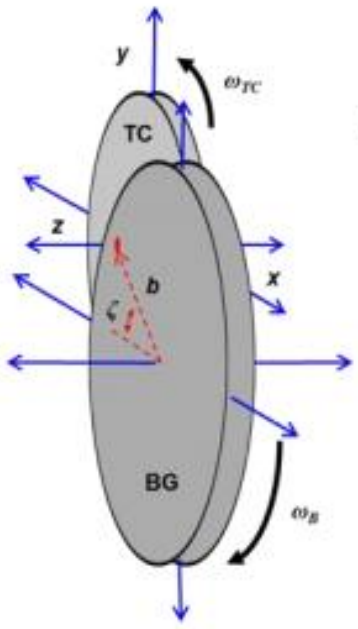

(a)

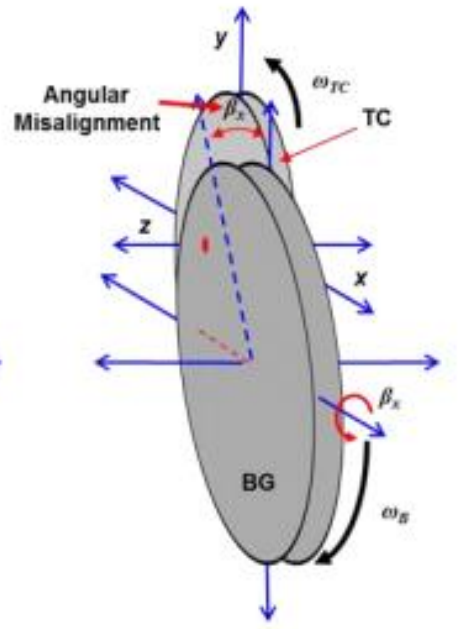

(b)

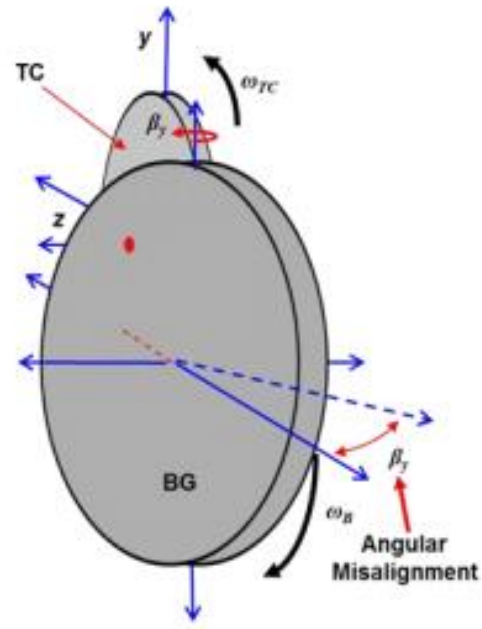

(c)

Figure 9. TC with (a) no static misalignment and BG with (b) angular misalignment about $x$ axis, and (c) angular misalignment about the $y$ axis [5].

The axial dynamics of the thrust collar fluid film are characterized by the stiffness and damping coefficients. The axial reaction-force model used by Cable et al. is,

$$
k_{z}+\boldsymbol{j} \Omega c_{z}=-\int_{r_{\text {left }}}^{R_{1}} \int_{\theta_{\min }}^{\theta_{\max }} \boldsymbol{p}_{z} r d r d \theta
$$

where $\boldsymbol{p}_{z}$ is the complex dynamic pressure in the lubricated area, and $r$ is the radius of the TC in the lubricated area.

The model for the dynamic reaction load for small motion about an equilibrium position with no misalignment is 


$$
F_{T C}=-k_{z} \Delta_{z}-c_{z} \dot{\Delta_{z}}
$$

where $F_{T C}$ is the reaction force in the specified axis on the TC. $\Delta_{z}$ is the axial displacement of the TC relative to the BG. To the author's knowledge, there are no published results on the measured dynamic characteristics $\left(k_{Z}, c_{Z}\right)$ of a lubricated TC. 


\section{STATEMENT OF WORK}

The primary objectives for this study are: (a) measure $k_{Z}$ and $c_{Z}$ using a thrust

collar test rig, and (b) determine the effects of changes in the applied axial force and spin speed. The author will take static and dynamic displacement measurements of the TC and bull wheel (BW) at the TC overlap interface area. With measured axial displacements of the TC and $\mathrm{BW}$, the author will identify measured $k_{Z}$ and $c_{Z}$ values. These results will be compared to predictions from the model by Cable et al. [16].

To obtain the dynamic characteristics outlined above, the author conducts tests on a rig proposed by Childs, Phillips [17]. The test rig is shown in Fig. 10. The dimensions of the TC and the BW closely match that of an industrial IGC. The two shafts are not coupled by gears and are driven by two independent motors. Lubricant is sprayed from below the TC-BW interface with a spray bar. The axial load is applied to the high speed shaft (HSS) by a static loader (described further below). An impact hammer is used to strike the HSS, and the resulting motion is measured by several displacement probes located on the BW, TC, HSS, and BW shaft. 


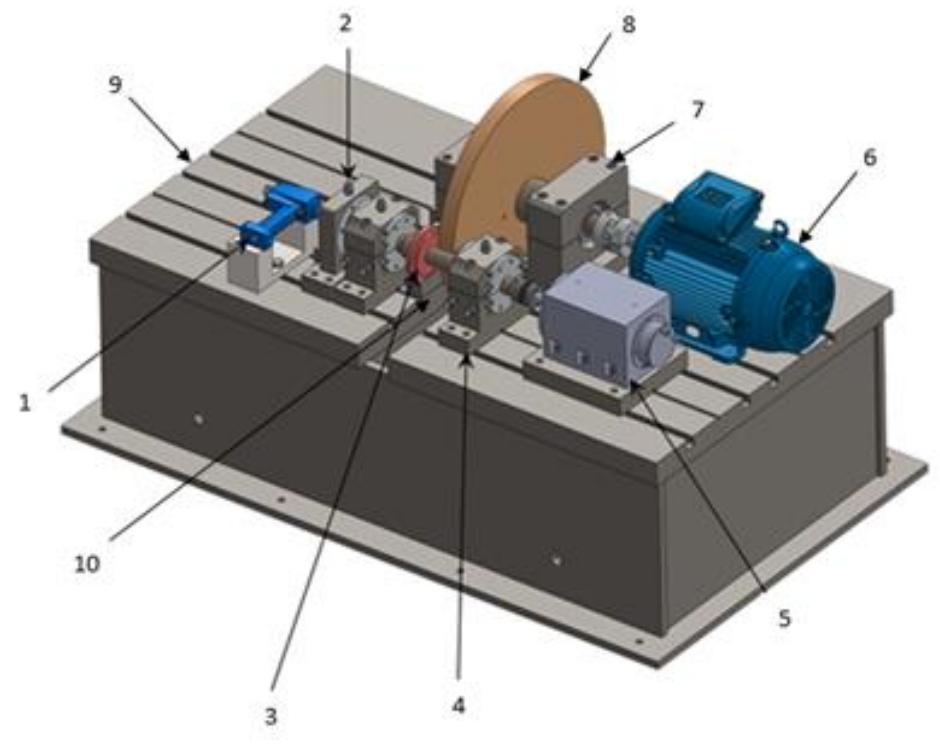

\begin{tabular}{|l|}
\hline 1. Impact Hammer \\
\hline 2. Static Loader \\
\hline 3. Thrust Collar \\
\hline 4. Hydrostatic Bearings \\
\hline 5. High Speed Motor \\
\hline 6. Low Speed Motor \\
\hline 7. Ball Bearings \\
\hline 8. Bull Wheel \\
\hline 9. Bed Plate \\
\hline 10. Spray Bar \\
\hline
\end{tabular}

Figure 10. View of the main test section.

Tests are conducted with HSS speeds of 5, 7.5, and $10 \mathrm{krpm}$. The speed of the BW shaft is varied according to the following equation,

$$
\omega_{B W}=\frac{\omega_{H S S}}{N}
$$

where $N$ is an assumed gear ratio equal to 11.67. A static load is applied to the HSS, creating a range of unit loads, where the unit load is defined as the applied static load divided by the TC overlap area. Three axial average resultant static forces $\left(\bar{F}_{z}\right), 200,300$, and $400 \mathrm{~N}$, will be applied at each spin speed. 


\section{TEST RIG DESCRIPTION}

The test rig is designed to operate similarly to a thrust collar in an integrally geared compressor, except the applied axial load capacity is smaller than a typical IGC. For this study the reason for testing at smaller loads is outlined below in the data analysis section. The test rig can be broken into four major sections: the LSS assembly, the high speed shaft (HSS) assembly, ancillary equipment, and the data acquisition system.

Returning to Fig. 10, the data acquisition system and relevant sensors are not shown. The notable ancillary items in Fig. 10 are the impact hammer (1), the static loader (2), the bed plate (9), and the spray bar (10). The TC (3), hydrostatic bearings (4), and high speed motor (5) are all included in the HSS assembly. The LSS assembly consists of the LSS, low speed motor (6), ball bearings (7), and BW (8).

\subsection{LSS Assembly}

Figure 11 shows a cross section view of the LSS. A steel BW is attached to the Inconel LSS by an interference fit. The LSS is attached to the bedplate using three ball bearings and is connected to the motor using a jaw-type coupling. The drive end (DE) is on the right, and the non-drive end (NDE) is on the left. 


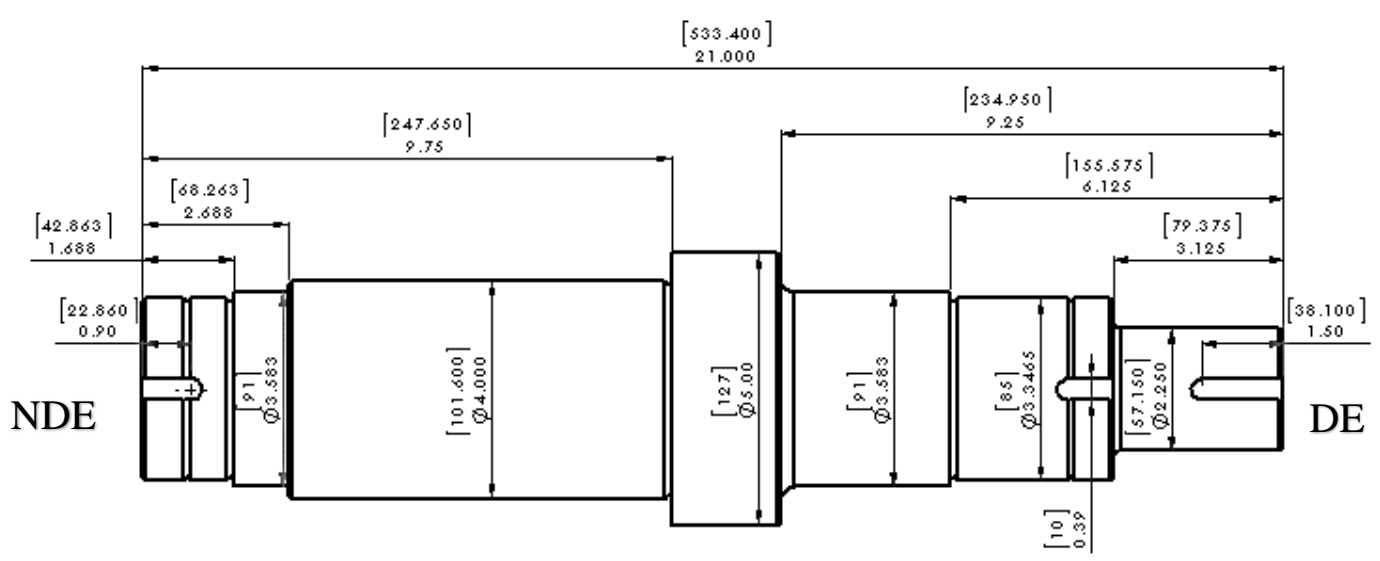

Figure 11. Low speed shaft. All dimensions are in [mm] in.

Two angular-contact ball bearings are fitted in a back-to-back arrangement on the DE. These bearings react axial and radial forces. On the NDE the LSS is connected by a single deep-groove ball bearing. This bearing only reacts radial loads while permitting axial growth. Both sides of the bearing are secured by a locking washer and nut. The bearing housing is split into upper and lower halves, allowing the rotor to be dropped into place.

The BW was fitted in the middle of the shaft, and is shown in Fig. 12. Typically, the TC and BW have the same taper angle, ranging from 1-3 degrees. For this set of tests, the TC and BW were both machined to support a 2 degree taper \pm 0.1 degrees. The taper angle started at the edge of the BW and ran slightly over 2.5 centimeters down the face. This area ensures that the overlap between the TC and the $\mathrm{BW}$ is complete and forms a hydrodynamic wedge. 

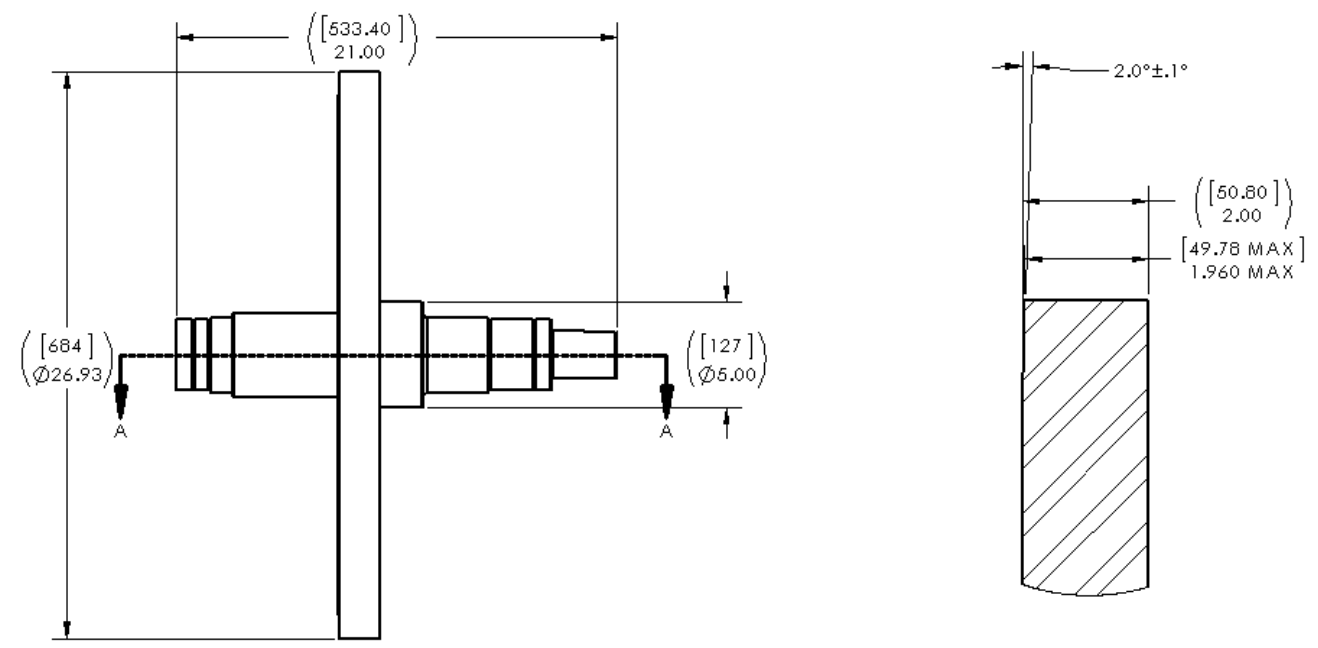

Figure 12. Schematic of the BW attached to the LSS. All dimensions are in [mm] (in).

The LSS is driven by a 15 kilowatt motor with a maximum speed of 3,540 rpm.

The speed is controlled by a variable frequency drive.

\subsection{HSS Assembly}

Figure 13 displays the HSS shaft assembly. It operates with a steel TC and aluminum thrust disk (to apply the axial thrust load) attached to an Inconel shaft. The shaft is supported on the bedplate by two hybrid (hydrostatic and hydrodynamic) bearings and coupled to the motor using a bellows-type coupling. 


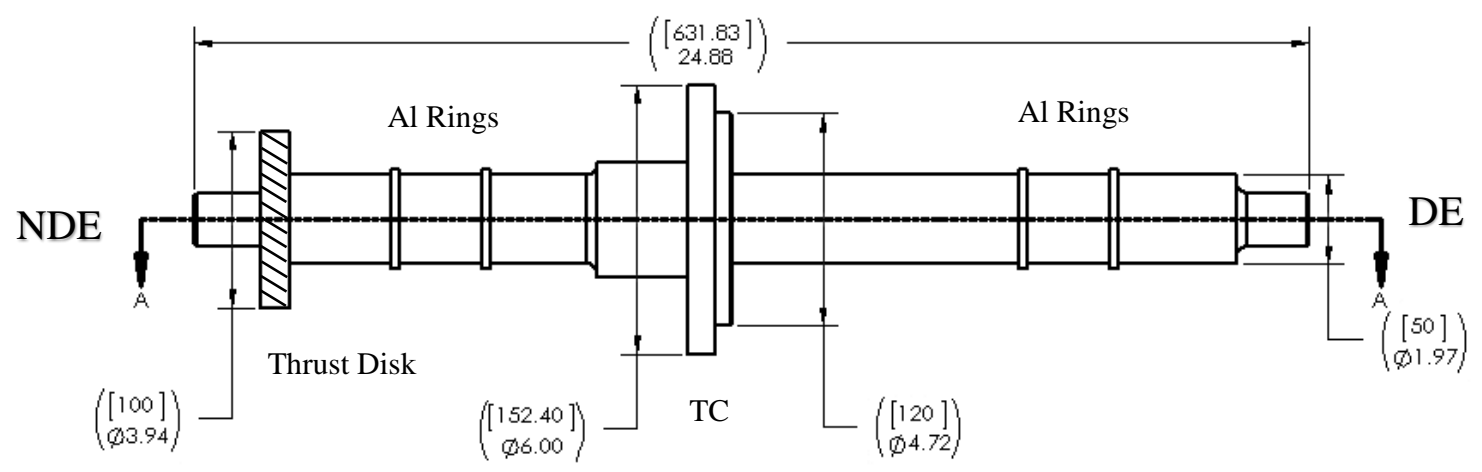

Figure 13. HSS assembly, includes the TC. All dimensions are in [mm] (in.).

The TC is fitted on to a shoulder in the middle of the shaft. The taper angle on the face of the TC cannot be seen in this figure. On the NDE, the thrust disk is shaded in the figure and has a diameter of $10 \mathrm{~cm}$. Two sets of two aluminum rings are fitted to the shaft on each side of the TC and help to prevent leakage from the bearings. These four aluminum rings are shown in Fig. 13. Air buffer seals, not shown in the figure, prevent the oil from escaping. The lubricating oil is ISO VG 32.

The thrust-disk pneumatic static loader, shown in Figure 14, is used to apply a constant axial force on the HSS. This force is transmitted through the HSS to the lubricated area. A pressure regulator located on the high pressure side of the loader maintains a constant axial force. Air enters from the regulator to the top of the loader and travels to a plenum where the pressure applies a load on to the thrust disk. Air exits through labyrinth seals on either side of the plenum. The pneumatic loader was calibrated with a strain gauge on a rigid fixture to confirm static load versus supply pressure.

The applied unit-load on the TC is defined as 


$$
P_{T C}=\frac{\bar{F}_{z}}{0.5 * A_{T C}}
$$

where $\bar{F}_{Z}$ is calculated from the pressure that the pneumatic load applies, and $A_{T C}$ is the overlap area between the TC and the BW. The 0.5 in Eq.(7) arises because it is assumed that only the converging half of the TC lubricated area carries the load, since the other half (diverging) is cavitated. The three static, axial forces tested are $\bar{F}_{z}=200,300$, and $400 \mathrm{~N}$ which correspond to unit-loads of $P_{T C}=3.3,4.8$, and 6.2 bars.

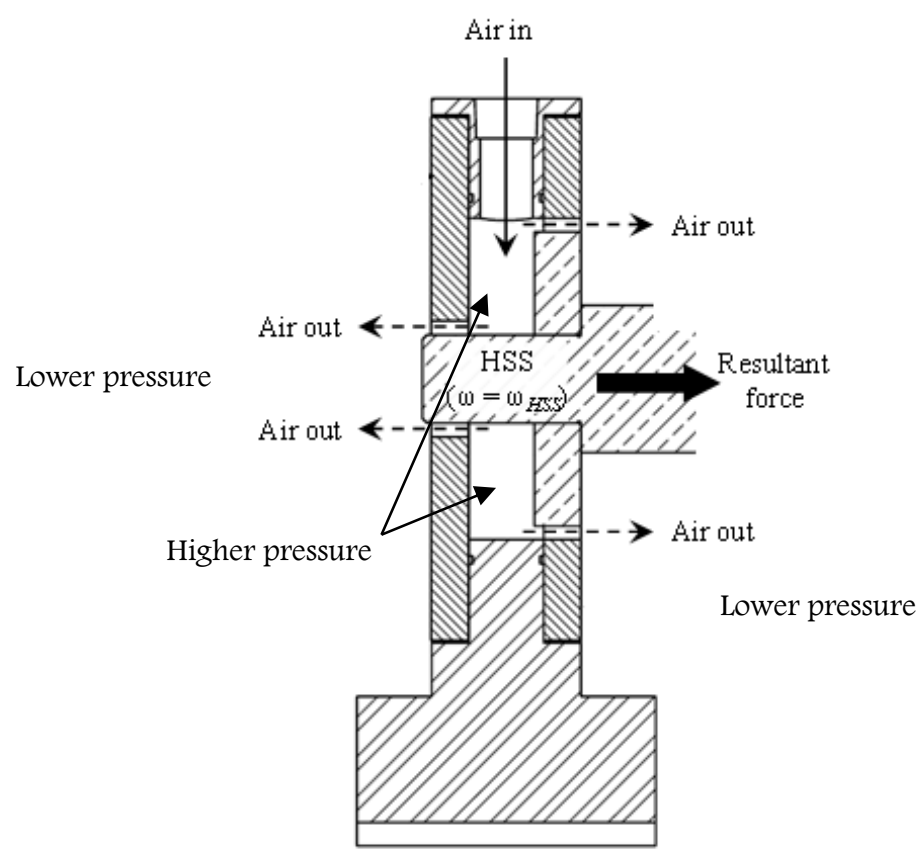

Figure 14. Cross-section view of the pneumatic loader.

Two hybrid bearings support the HSS to the bed plate. Their lubricant is pressurized by a hydraulic power supply system with a separate pump, reservoir, heat exchanger, filter, and control electronics. 
The HSS is powered by a 22 kilowatt motor with a maximum speed of $20 \mathrm{krpm}$. A variable-frequency drive allows the operator to set the speed. A chiller provides glycol to cool the motor.

\subsection{Impact Hammer}

An automated impact hammer strikes the NDE of the HSS. The automated program produces a random time-lapse between one and three seconds, before striking the shaft again. This variability will help during data processing to average out any geometrical difference of the two shafts. In fact, care and attention would be required to insure that the two rotors had even nearly the same relative circumferential position during separate impacts. 


\subsection{Ancillary Equipment}

A spray bar, mounted underneath the BW/TC overlap area, provides the lubricant via a geared pump. The pump operates on a VFD, and a flowmeter monitors the flow. Tests were run with a flow-rate of 19 liters per minute. An accumulator contains enough lubricant to ensure a safe run-down in the event of a power failure.

The bedplate holds all of the lubricant. Baffles inside the bedplate prevent vortices and also allow particulates to settle. A slot in the bedplate allows for the lubricant to return to the reservoir and also allows the BW to sit below the top of the bedplate. Keyways ensure that the two shafts maintain relative parallelism. A cover is placed over the BW and TC during testing and helps to prevent lubricant loss due to spraying. 


\subsection{Additional Instrumentation and Data Acquisition}

Figure 15 displays all of the instrumentation necessary to make the static and dynamic measurements of the thrust collar.

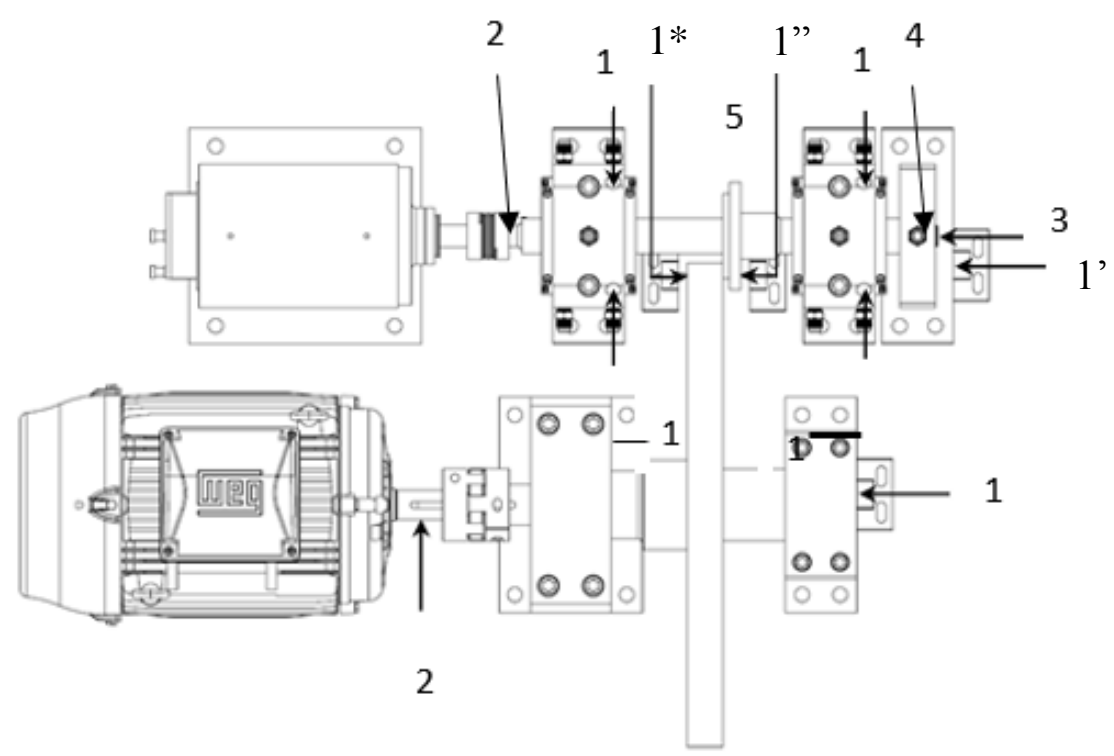

Figure 15. Top view showing the position of all relevant sensors.

Eddy-current displacement probes (1) measure the axial and lateral displacement of different important locations on the test rig. $1^{*}, 1$ ', and 1 " identify axial probes at the $\mathrm{BW}$, the HSS, and the TC, respectively. $1 *$ and 1 " measure the axial positions of the BW and TC near the overlapping surface. 1' measures the axial position of the entire HSS.

The axial transient displacement measurements of the TC, 1"; and BW, $1^{*}$, are necessary to determine the $k_{z}$ and $c_{z}$ coefficients of the TC lubricated area. All of the samples are measured at 10,240 $\mathrm{HZ}$. 
Probes (1) located at the HSS hyrbid bearings measure the lateral displacement of the HSS in the $x$ and $y$ direction. Keyphasors (2) are used to measure the rotational speed of the HSS and LSS. A piezoelectric load cell (3) measures the instantaneous force created by the impact hammer. A pressure transducer (4) measures the differential pressure across the thrust disk and is used to define the static axial force from the load. A flowmeter (5), not shown in the figure, measures the flow of lubricating oil to the spray bar. Thermocouples monitor the temperature of the lubricating oil and the hydrostatic bearing oil.

The data acquisition system utilizes National Instrument C-Series modules. A LabVIEW VI controls the data acquisition. 


\section{PREDICTIVE CODE}

The inputs of Cable's code [5] are the geometry of the TC and BW, including shaft static misalignments, lubricant properties, spin speeds, and axial load. The code then predicts the TC's required lubricant flow-rate for lift-off, power loss, temperature rise, and dynamic coefficients. Table 1 shows the inputs used for this report, which match the test rig.

Table 1. TC predictive code inputs that match the test rig.

\begin{tabular}{|l|l|}
\hline Code Input & Value \\
\hline Radius to end of taper & 0.342 (meter) \\
Thrust collar radius & 0.06 (meter) \\
Distance between gear centers & 0.380 (meter) \\
Lubricant & ISO VG 32 \\
Lubricant Temperature & 30 C \\
Taper Angle (BG) & $2(\mathrm{deg})$ \\
Taper Angle $(\mathrm{TC})$ & $2(\mathrm{deg})$ \\
Shaft Static Misalignments & \\
$\left(\beta_{x}, \beta_{y}, \mathrm{~B}_{x}\right.$, and $\left.\mathrm{B}_{y}\right)$ & $0($ deg) \\
Axial Load & varies per test point \\
TC Spin Speed & varies per test point \\
BG Spin Speed & varies per test point \\
\hline
\end{tabular}

The code is used to obtain predicted $k_{z}$ and $c_{z}$ values. 


\section{STATIC STIFFNESS TESTS}

Static tests were conducted to characterize the TC's static load-deflection characteristics. To perform a static test, one speed point is tested at a time. To begin a rotating test, the HSS and LSS are spun to their predetermined speeds. The HSS spin speed is always 11.67 times faster than the LSS spin speed, according to the assumed gear ratio. The spray bar applies the lubricating oil in the clearance between the thrust collar and the bull wheel. The operator sets the flow to nineteen liters per minute. This meets the recommended flowrate for the lubricated area, and excess oil will spill into the baseplate reservoir.

The axial load is applied to the end of the HSS. For a static tests, the static load is varied by changing the pressure on the load disk. At $\bar{F}_{z}=100,200,300,400$, and $500 \mathrm{~N}$ the displacements are measured at the TC, $\bar{\Delta}_{\mathrm{TC}}\left(1\right.$ " in Fig. 15) and the BW, $\bar{\Delta}_{\mathrm{BW}}(1 *$ in Fig. 15). The displacements are measured for $0.4 \mathrm{~s}$, (several revolutions of both the BW and TC). $\bar{\Delta}_{\mathrm{TC}}$ and $\bar{\Delta}_{\mathrm{BW}}$ are averaged at each point.

Averaging is done because measured runout is significant. Figure 16 displays several revolutions of the $\mathrm{BW}$ and the $\mathrm{TC}$ during a static test. The average runout of the $\mathrm{BW}$ is approximately 0.05 millimeters, and the runout of the $\mathrm{TC}$ is 0.064 millimeters. Since the lubricated thrust area is displaced approximately $0.07 \mathrm{~mm}$ at the maximum axial load, the runout is quite large compared to the average clearance. 

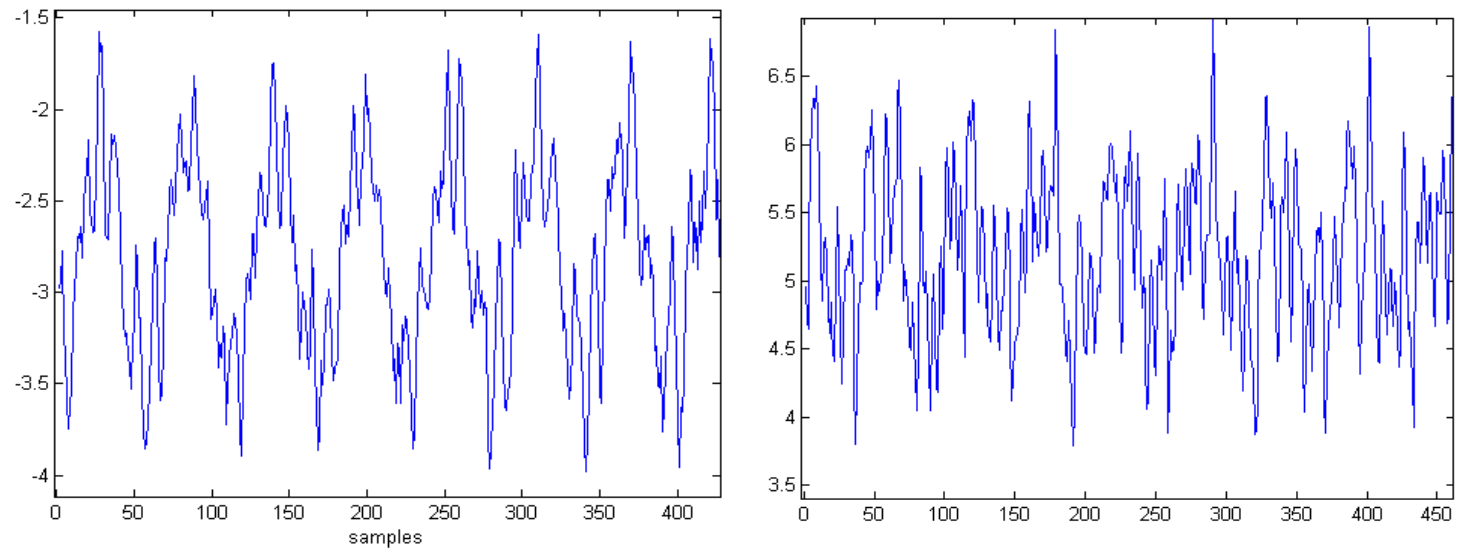

Figure 16. Runout of the BW (a) and TC (b).

After the samples have been averaged they are subracted to obtain the relative displacement, $\bar{\Delta}_{\mathrm{z}}=\bar{\Delta}_{\mathrm{TC}}-\bar{\Delta}_{\mathrm{BW}}$. Figure 17 shows three separate tests for $\bar{\Delta}_{\mathrm{z}}$ versus $\bar{F}_{\mathrm{z}}$, for a HSS spin speed of $5 \mathrm{krpm} . \overline{F_{z}}$, is increased in increments of $100 \mathrm{~N}$, then decreased in a similar fashion. No hysteresis occurs in any of the tests. Three tests are measured at each $\omega$ to quantify repeatability. The type of line that best fits the data is an exponential function

$$
\overline{\mathrm{F}}_{\mathrm{z}}=\mathrm{A}_{0} * \mathrm{e}^{\left(B_{0} \bar{\Delta}_{\mathrm{z}}\right)}
$$

where $A_{0}$ and $B_{0}$ are coefficients describing the relationship of the exponential function of $\bar{k}_{z}$. The slope of this line yields the static axial stiffness

$$
-d \bar{F}_{z} / d \bar{\Delta}_{z}=\bar{k}_{z}=\left(A_{0} * B_{0}\right) * e^{\left(B_{0} \bar{\Delta}_{z}\right)}
$$




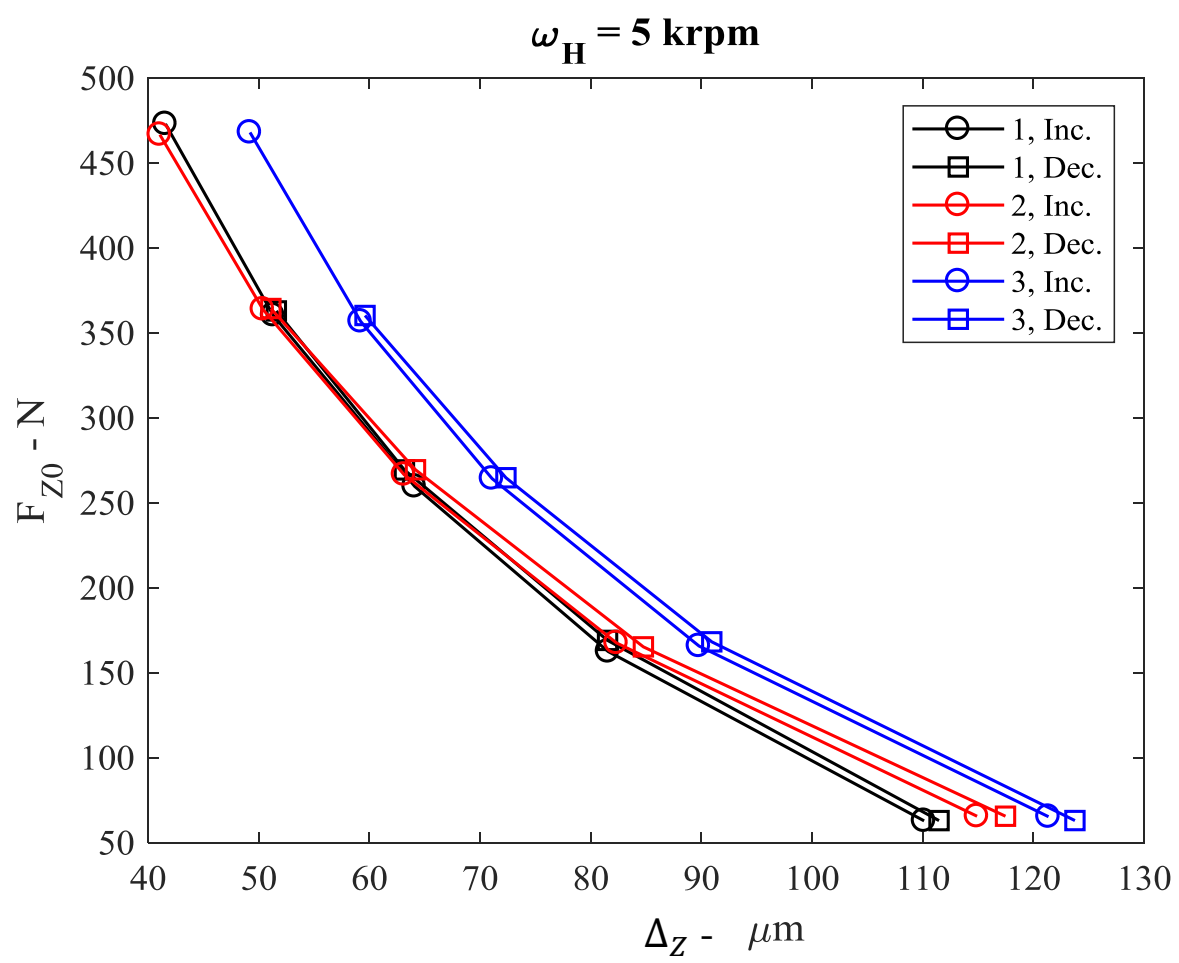

Figure 17. Axial force versus axial displacement of lubricated area

Figure 18 displays predicted and measured $\bar{k}_{z}$ as a function of $\bar{F}_{z}$ for the three tested speeds. The error bars represent the three tests conducted at each test point. Both measured and predicted $\bar{k}_{z}$ values increases for increasing $\bar{F}_{\mathrm{z}}$. Measured and predicted $\overline{\mathrm{k}}_{\mathrm{z}}$ for the $\omega=5 \mathrm{krpm}$ case are very similar. For increasing $\omega$ measured $\bar{k}_{z}$ values increase and predicted $\bar{k}_{z}$ decreases. Oil-flinging could explain the difference in measured and predicted results. At higher speeds, more oil is flung out of the lubricated area. This creates a starved fluid-film, resulting in a higher stiffness. 


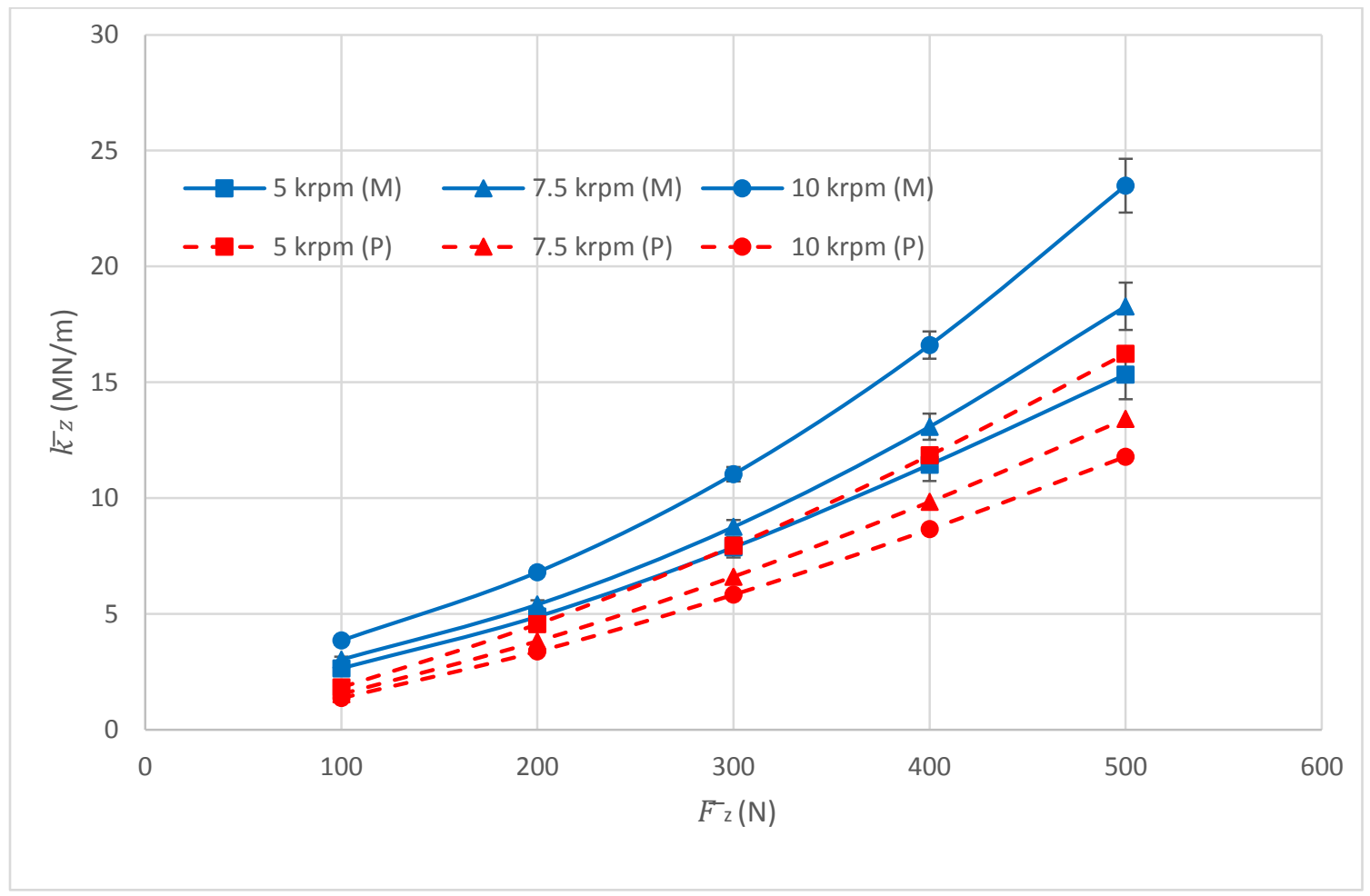

Figure 18. Predicted and Measured $\bar{k}_{z}$ as a function of $\bar{F}_{z}$ for $\omega$. 


\section{DYNAMIC TESTS}

\subsection{Test Procedure}

To perform a dynamic test, the two shafts are brought to speed, the lubricant is applied. The axial loader then applies the predetermined static load set point. The impact hammer strikes the end of the HSS. At each impact, the dynamic displacement measurements of the TC $\left(\Delta_{T C}\right)$ and the $\mathrm{BW}\left(\Delta_{B W}\right)$ are recorded before, during, and after the impulse. The dynamic motion of the TC and BW are measured by the displacement probes shown in Fig. 15 as 1" and 1*, respectively. Figure 19 displays the TC and BW displacements for a single hammer impact. For this test point, the impact occurred at 0.55 seconds.

(a)

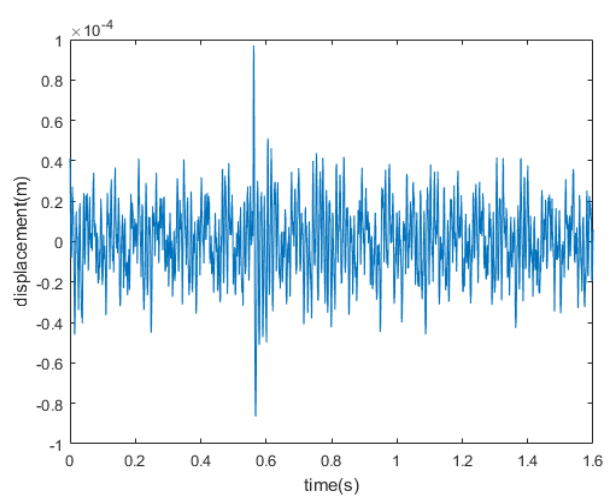

(b)

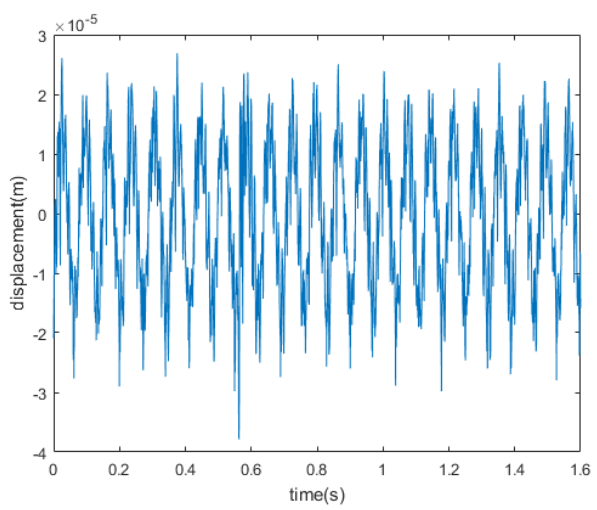

Figure 19. (a) TC axial displacement $\Delta_{T C}$ (from 1"), and (b) BW axial displacement $\Delta_{B W}\left(\right.$ from $\left.1^{*}\right)$ for a single impact.

The TC and BW disks were not perfectly set at $90^{\circ}$ from their shafts. The resulting tilt angles, along with an imperfectly smooth face creates a runout on both faces of the TC and the BW. Runout at the HSS speed and multiples of the LSS speed obscures the transient data. The hammer will strike the shaft 100 times during a test, and 
the resulting data will be averaged to reduce the effects of runout. Figure 20 displays the averaged TC and BW displacements for 100 different impacts. The runout effects are largely eliminated by averaging the samples.

(a)

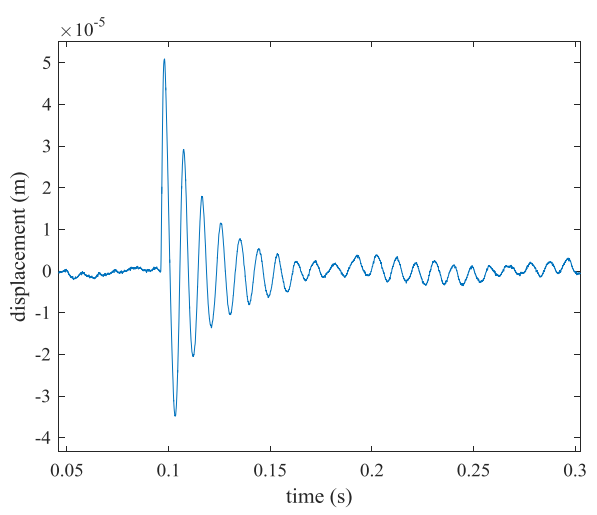

(b)

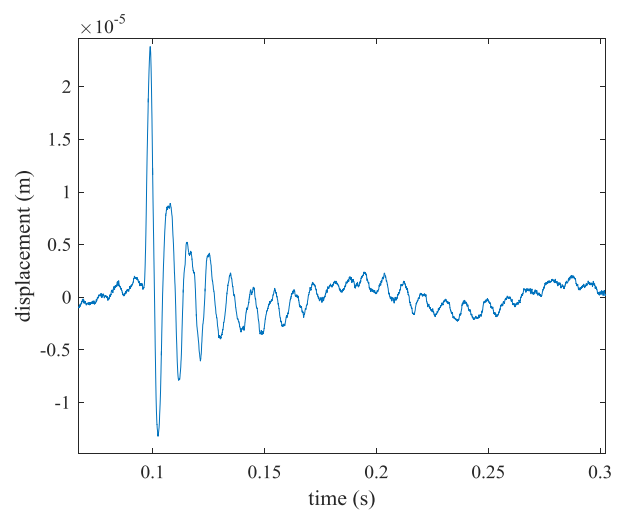

Figure 20. (a) $\left(\Delta_{T C}\right)$ and (b) $\left(\Delta_{B W}\right)$ measurements averaged over 100 impacts at $\bar{F}_{z}=200 \mathrm{~N}$ and $\omega=10 \mathrm{krpm}$. 


\subsection{Data Analysis}

This section outlines the procedure for turning dynamic displacement measurements of the $\mathrm{BW}$ and $\mathrm{TC}$ into estimated dynamic reaction measurements. Figure 21 displays the lubricated area of the TC, modeled as $c_{z}$ and $k_{z}$, (from Eq. 5). The impact hammer strikes the HSS. The variables $\mathrm{z}_{T C}(t)$ and $\mathrm{z}_{B W}(t)$ are the displacements of the TC and BW, measured by probes $1^{\text {" }}$ and $1^{*}$, respectively. $f(t)$ is the force applied from the impact hammer.

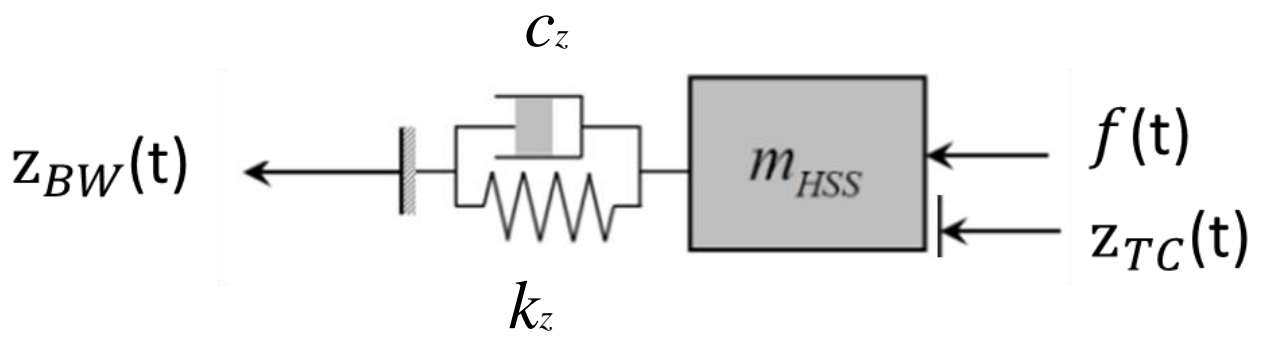

Figure 21. Model for axial vibration of the TC.

$\Delta_{Z}$ is the relative displacement of the lubricated area calculated once $\mathrm{z}_{T C}(t)$ and $\mathrm{z}_{B W}(t)$ have been averaged. They are subtracted to obtain

$$
\Delta_{\mathrm{z}}(t)=\mathrm{z}_{T C}(t)-\mathrm{z}_{B W}(t)
$$

The equation of motion describing this system is

$$
m_{H S S} \ddot{\mathrm{z}}_{T C}=f(t)-c_{z} \dot{\Delta_{z}}-k_{z} \Delta_{z}
$$

rearranging Eq. (10) and combining it with Eq. (11) yields 


$$
m_{H S S} \ddot{\Delta}_{z}+c_{z} \dot{\Delta}_{z}+k_{z} \Delta_{z}=f(t)-m_{H S S} \ddot{\mathrm{z}}_{B W}
$$

where $\mathrm{z}_{B W}$ is the displacement of the $\mathrm{BW}$.

Figure 22 displays $\Delta_{\mathrm{z}}(t)$ for the $7.5 \mathrm{krpm}, 300 \mathrm{~N}$ test case. Several peaks are visible, and can be used to extract $k_{z}$ and $c_{z}$ using the log decrement and the damped natural frequency. Note: the author made no attempt to determine the transfer function $\boldsymbol{\Delta}_{z} / \boldsymbol{f}$ of Eq. (12).

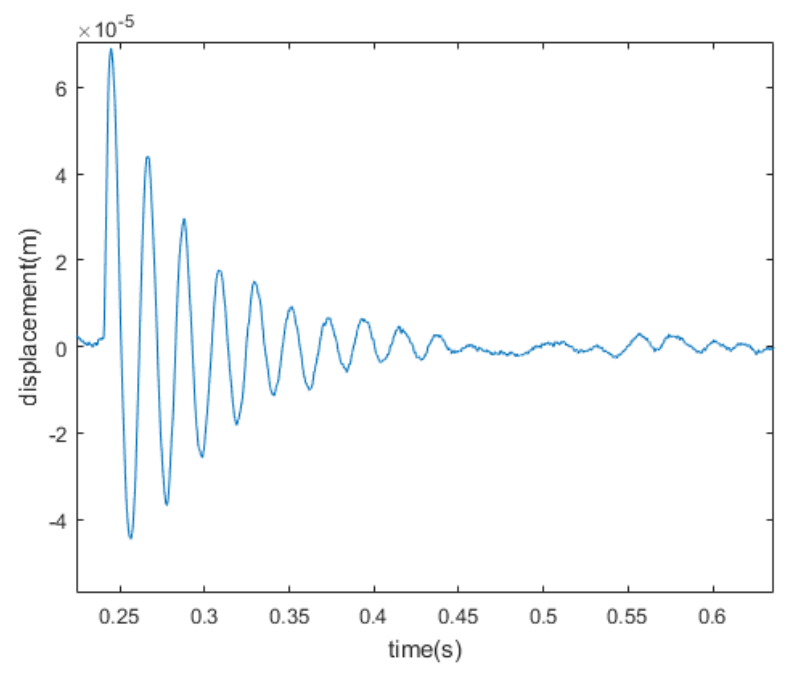

Figure 22. $\Delta_{z}(t)$ for $\omega=7.5 \mathrm{krpm}$ and $F_{z}=300 \mathrm{~N}$.

Once the peaks are picked, the logarithmic decrement is

$$
\delta=\frac{1}{n-1} \ln \left(\frac{Y_{1}}{Y_{n}}\right)
$$

where, $Y_{1}$ and $Y_{n}$ are the displacement values at the chosen peaks, and $n-1$ is the number of cycles between the peaks. The damped natural frequency is

$$
\omega_{d}=\frac{2 \pi}{T_{d}}
$$


where $T_{d}$ is the period of the damped motion. The damping factor, $\zeta$, is

$$
\zeta=\frac{\delta}{\sqrt{(2 \pi)^{2}+\delta^{2}}}
$$

Using the damping factor and damped natural frequency, the natural frequency is

$$
\omega_{n}=\frac{\omega_{d}}{\left(1-\zeta^{2}\right)^{0.5}}
$$

Once $\omega_{n}$ and $\zeta$ are calculated the stiffness and damping can be determined

$$
\begin{gathered}
c_{z}=2 \zeta m_{H S S} \omega_{n} \\
k_{z}=m_{H S S} \omega_{n}^{2}
\end{gathered}
$$

where $m_{H S S}$ is the mass of the HSS $(12.8 \mathrm{~kg})$. Figure 23 shows the measured static stiffness values $\bar{k}_{z}$ (obtained from the static test) and the measured dynamic stiffness values $k_{z}$ (obtained from Eq. 18). The dynamic $k_{z}$ values are much smaller than the values obtained from the static-load deflection model. 


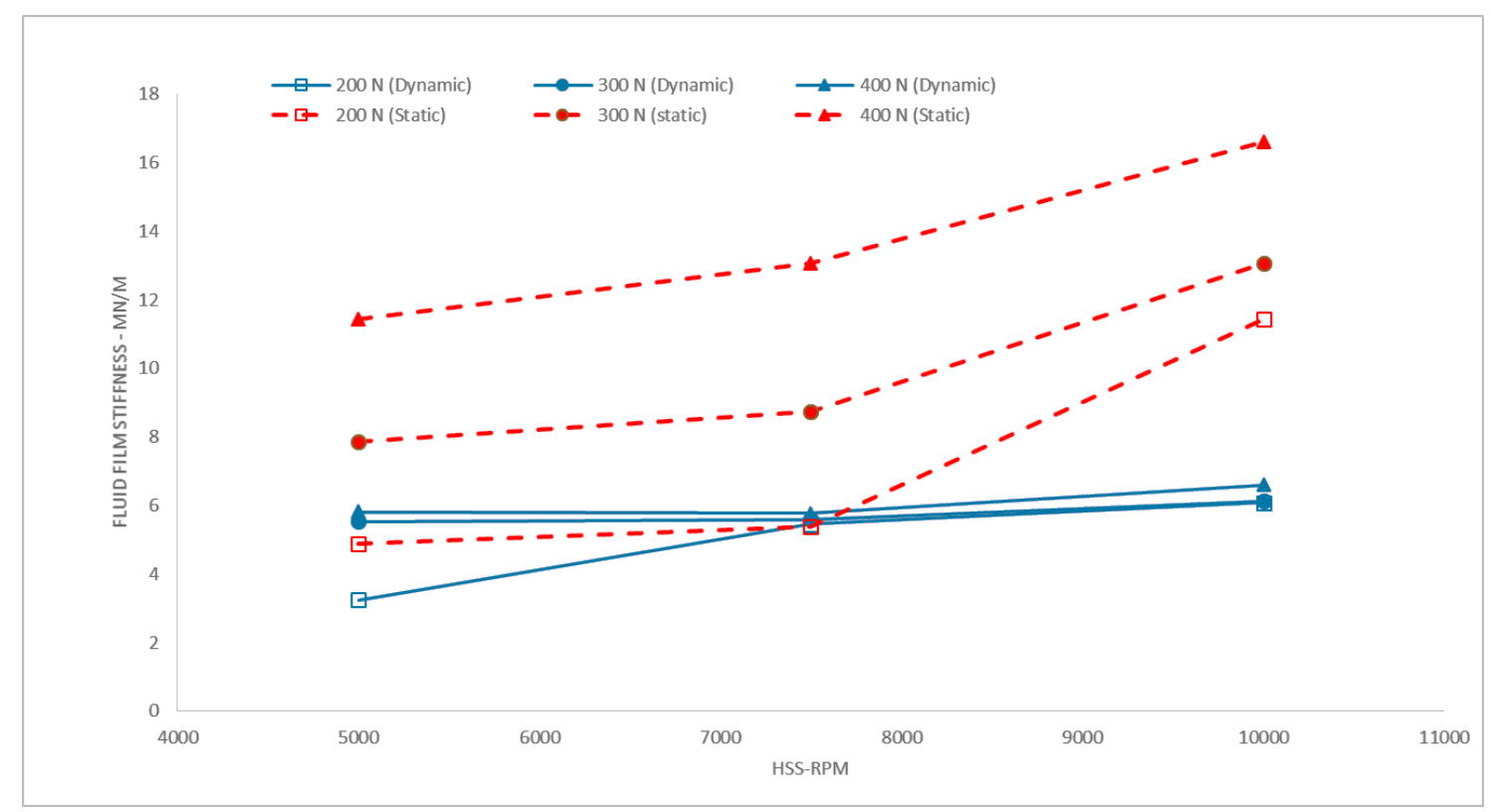

Figure 23. Measured static and dynamic stiffness as a function of $\omega$.

This outcome leads to the conclusion that the model of Eq. (5) is inadequate and needs to be replaced with

$$
F_{T C}=-k_{z} \Delta_{z}-c_{z} \dot{\Delta}_{z}-m_{z} \ddot{\Delta}_{z}
$$

where $m_{z}$ is a virtual mass term ${ }^{1}$. This change leads to a new equation of motion

$$
\left(m_{H S S}+m_{z}\right) \ddot{\Delta}_{z}+c_{z} \dot{\Delta}_{z}+k_{z} \Delta_{z}=f(t)-m_{H S S} \ddot{z}_{B W}
$$

Using this model, the identified values of $\omega_{n}, \zeta$, and the measured static stiffness coefficient $\bar{k}_{z}$ are used to calculate

\footnotetext{
${ }^{1}$ The explanation of requirement for a virtual mass coefficient is not the authors. It arose in conversations with Dr. Dara Childs and a TAMU Ph.d candidate, Andrew Crandall.
} 


$$
\begin{gathered}
c_{z}=2 \zeta\left(m_{H S S}+m_{z}\right) \omega_{n} \\
m_{z}=\frac{\bar{k}_{z}}{\omega_{n}^{2}}-m_{H S S}
\end{gathered}
$$

\subsection{Limitations on 1 Degree of Freedom Assumption}

Large IGCs can have axial loads much higher than $400 \mathrm{~N}$ on the pinion shafts.

The test rig described in this report can also deliver much higher axial loads on the pinion shaft.

Figure 24 shows $\Delta_{z}(\Omega)$ for $\omega=5 \mathrm{krpm}$. For each $\bar{F}_{z}$, there are two peaks between 0 and $250 \mathrm{~Hz}$. The first peak displays the relative motion of the BW and TC. As $\bar{F}_{z}$ increases, the amplitude of the first peak no longer dominates. As the amplitude of the first peak approaches the second, the single degree of freedom model becomes invalid. At higher loads ( $>400 \mathrm{~N})$, a single degree of freedom model becomes significantly less accurate. 


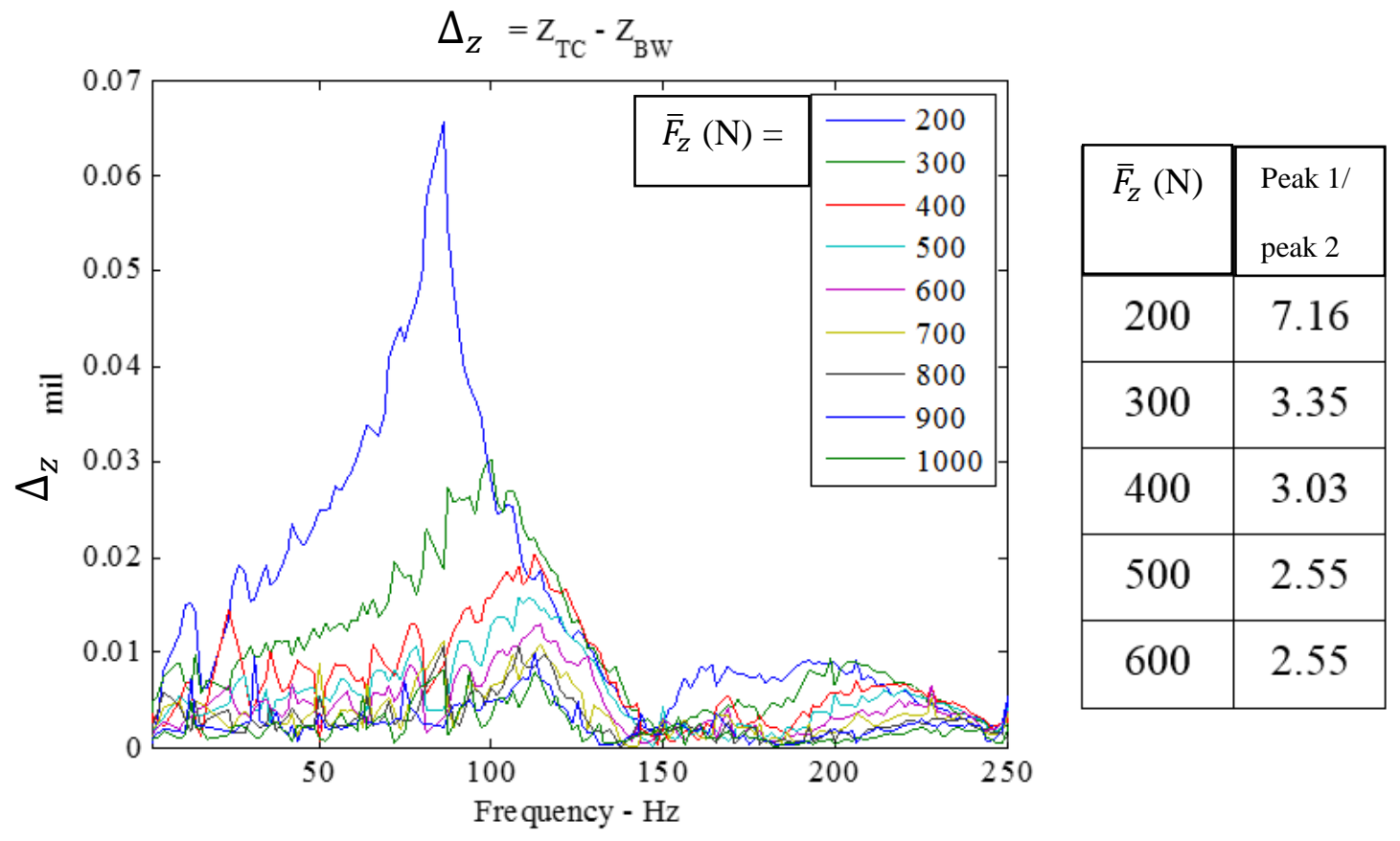

Figure 24. Relative displacement vs. frequency for $\bar{F}_{z}=200$ to $600 \mathrm{~N}$.

Figure 25 shows an additional difficulty in using the log dec technique at higher $\bar{F}_{Z}$ values. The relative displacement $\Delta_{Z}(t)$ is plotted for increasing $\bar{F}_{Z}$ values. The $300 \mathrm{~N}$ case has three well-defined peak amplitudes that show exponential decay and no other modes of vibration. For the 500, 700, and $900 \mathrm{~N}$ test cases the peaks are no longer clearly decreasing exponentially, and more than one frequency is evident. 

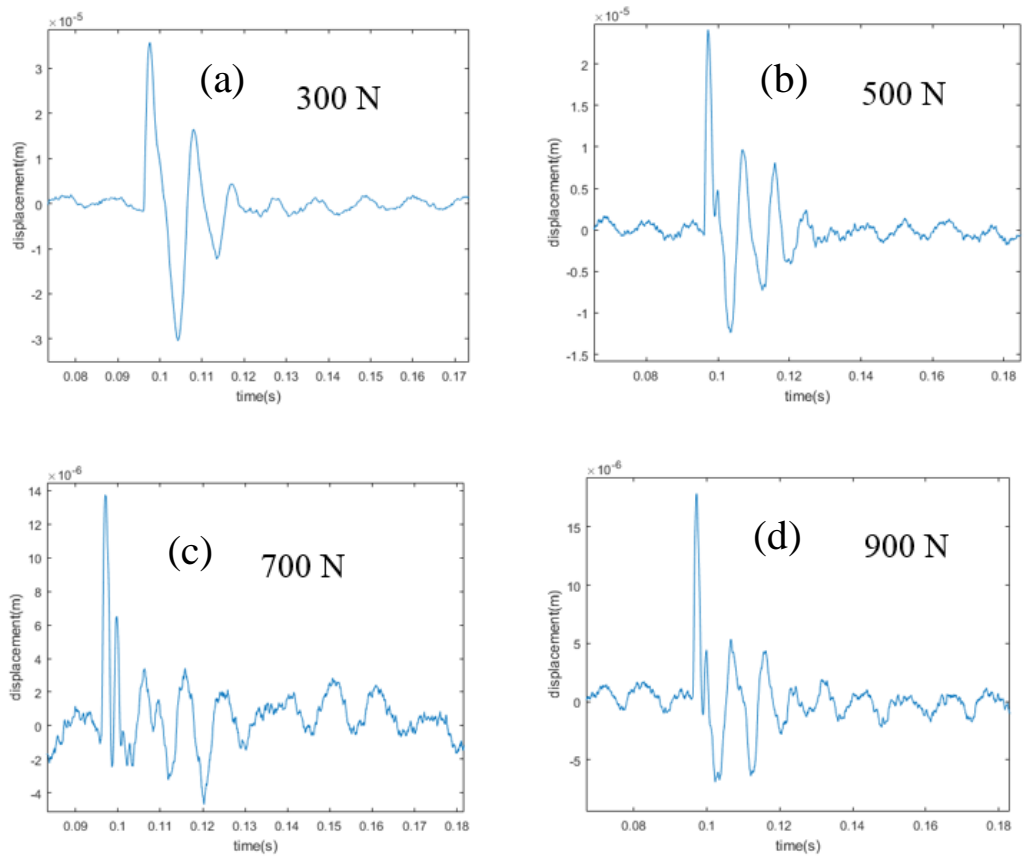

Figure 25. Relative displacement for $F_{Z}=300$ (a), 500 (b), 700 (c), and $900 \mathrm{~N}$ (d). 


\section{RESULTS}

\subsection{Temperature}

The lubricating oil starts a test at room temperature. There is no forced cooling mechanism for the TC oil lubricant. During tests, the friction from the TC and BW faces will heat the lubricant. Energy is also added through the supply pump. The bedplate acts as a temperature reservoir, and the lubricant is allowed to cool between tests. The TC lubricant oil temperature is measured before it is applied. The temperature increase during a test is shown in Figure 26 to be approximately $8^{\circ} \mathrm{C}$. The accuracy of the thermocouples is $\pm 0.1^{\circ} \mathrm{C}$. The average of the starting and finishing temperature of the $\mathrm{TC}$ oil $\left(30^{\circ} \mathrm{C}\right.$ for this figure $)$ is used as the input temperature for the predictive code.

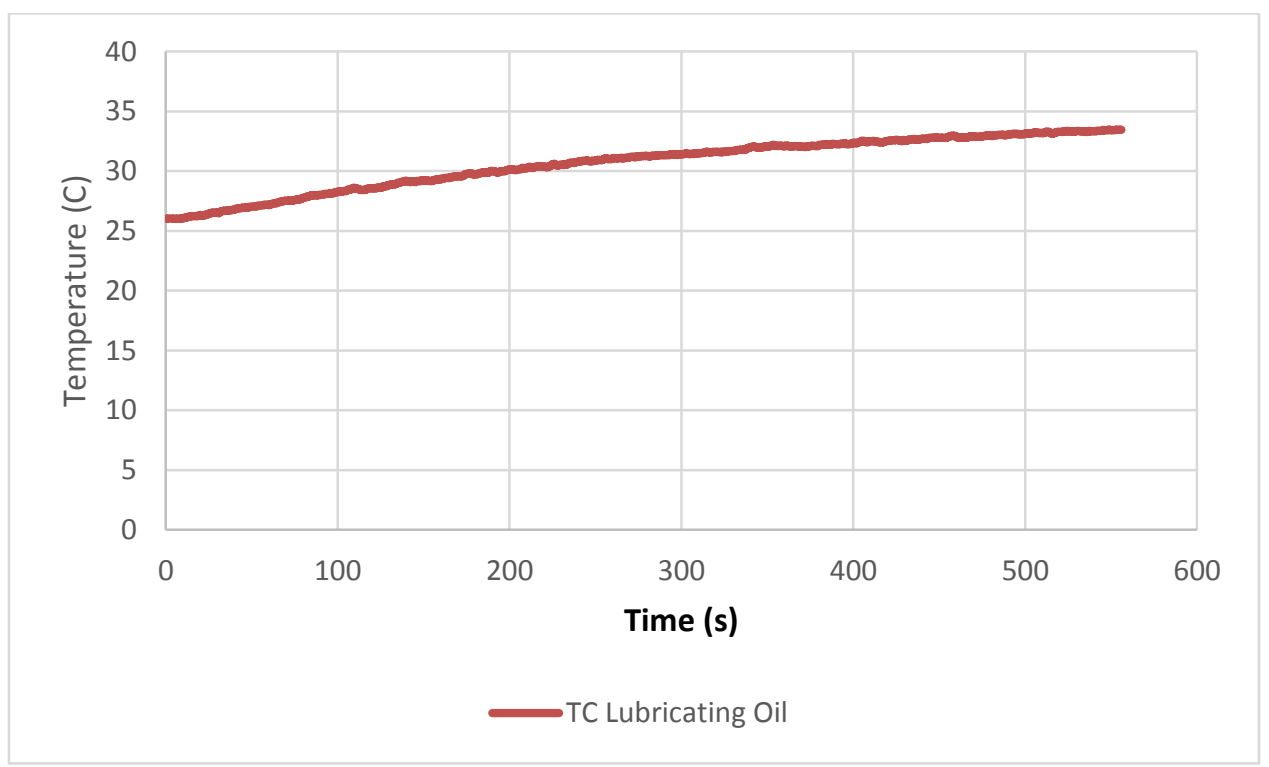

Figure 26. Temperature rise of the ISO VG 32 oil versus time for the TC. 


\subsection{Damping Coefficients}

Figure 27 displays estimated (from Eq. (21)) and predicted $c_{z}$ values for $\bar{F}_{z}=$ 200,300 , and $400 \mathrm{~N}$ and $\omega=5,7.5$, and $10 \mathrm{krpm}$. The dashed lines are predicted $c_{z}$, while the solid lines are estimated $c_{z}$. There is a slight increase in estimated $c_{z}$ as $\omega$ increases. Predicted $c_{Z}$ values decrease as $\omega$ increases. Both estimated and predicted $c_{Z}$ values increase versus increasing $\bar{F}_{z}$. The magnitude of the estimated values are significantly smaller than the predicted values, a factor of 10 in the $400 \mathrm{~N}, 5 \mathrm{krpm}$ test point. The predicted value is only 1.5 times higher than the estimated coefficient at the $200 \mathrm{~N}, 10 \mathrm{krpm}$ test point.

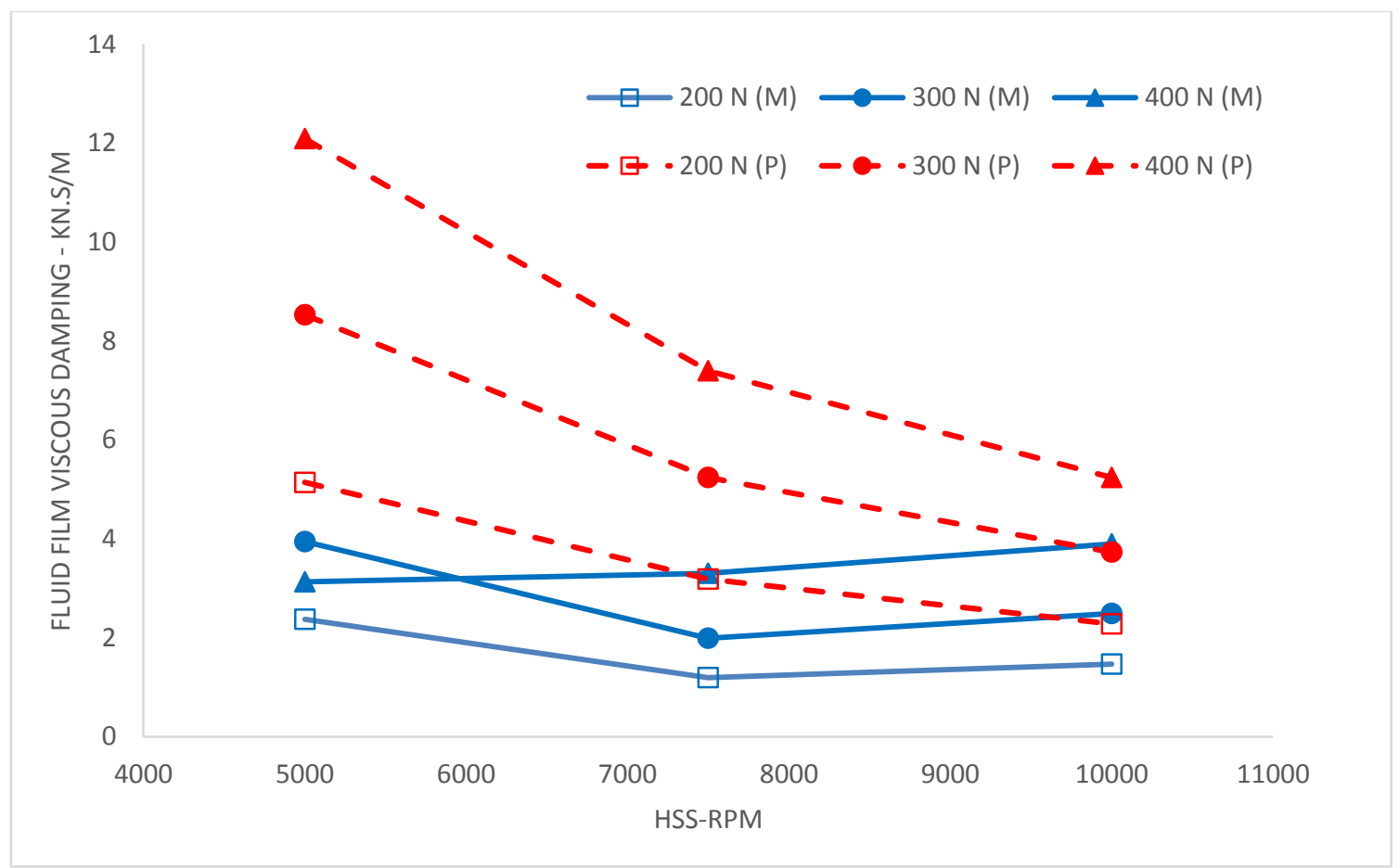

Figure 27. Measured and predicted $c_{z}$ versus $\omega$ for three $F_{z}$ values. 


\subsection{Virtual Mass Coefficient}

Figure 28 shows the virtual mass coefficient (calculated from Eq. 22) versus $\omega$

for three $\bar{F}_{z}$ values. $m_{z}$ increases for increasing $\bar{F}_{z}$ and increasing $\omega . m_{z}$ ranges from 0 to $19.5 \mathrm{~kg}$. This is comparable to the mass of the pinion shaft $(14.3 \mathrm{~kg})$. The code does not predict the virtual mass coefficient.

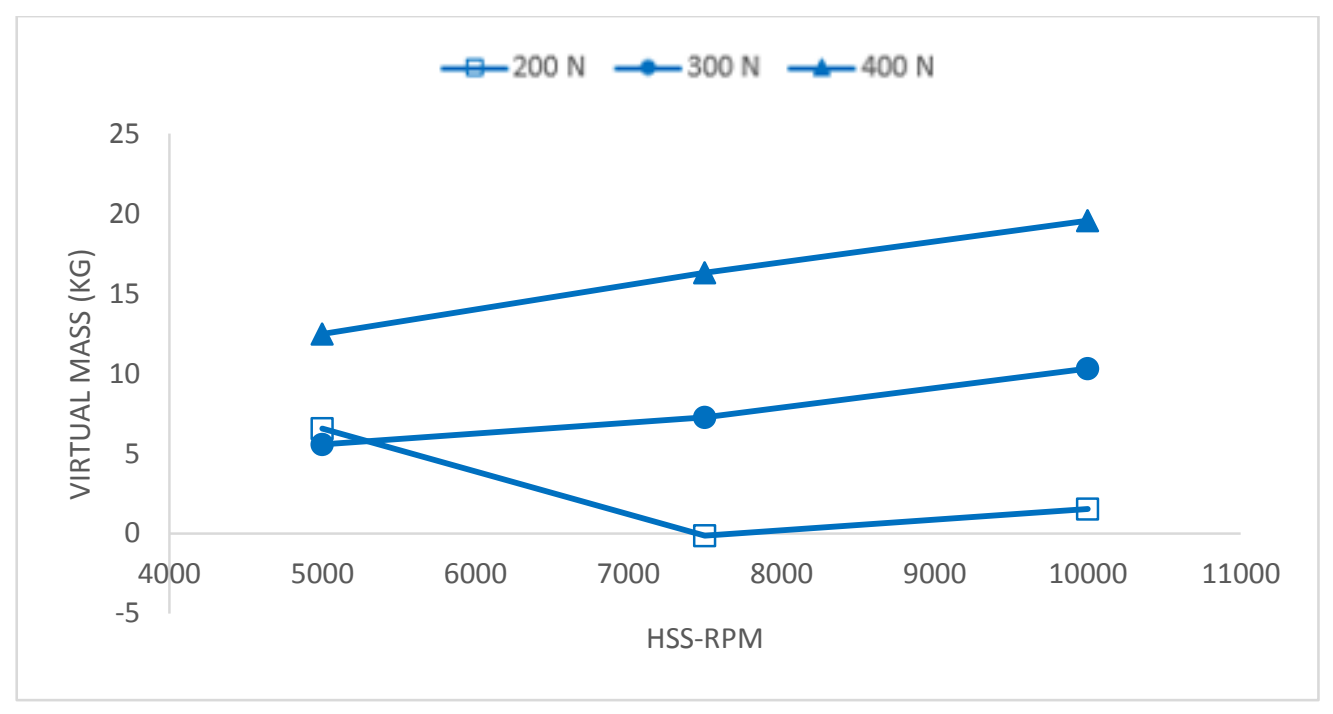

Figure 28. Virtual mass coefficient versus spin speed for three axial forces. 
8.

\section{UNCERTAINTY}

To calculate the total uncertainties for the dynamic stiffness and damping values, the author uses a Student's t-distribution. The error associated with the displacement measurements is $0.01 \%$. These values are negligible compared to the repeatability uncertainty. The standard deviation intervals calculated in the report look at only the variance. $\bar{k}_{z}$ is calculated from static-load deflection data.

The coefficients $c_{z}$ and $m_{z}$ are calculated using a log decrement technique. For each test, 100 impacts are recorded. To obtain the variance the 100 impacts are broken into four groups of 25 . The 25 impacts are averaged, and $m_{z}$ and $c_{z}$ are then calculated. Figure 29 shows the 4 averaged impacts. The mean and standard deviation are obtained from the four $m_{z}$ and $c_{z}$ values.

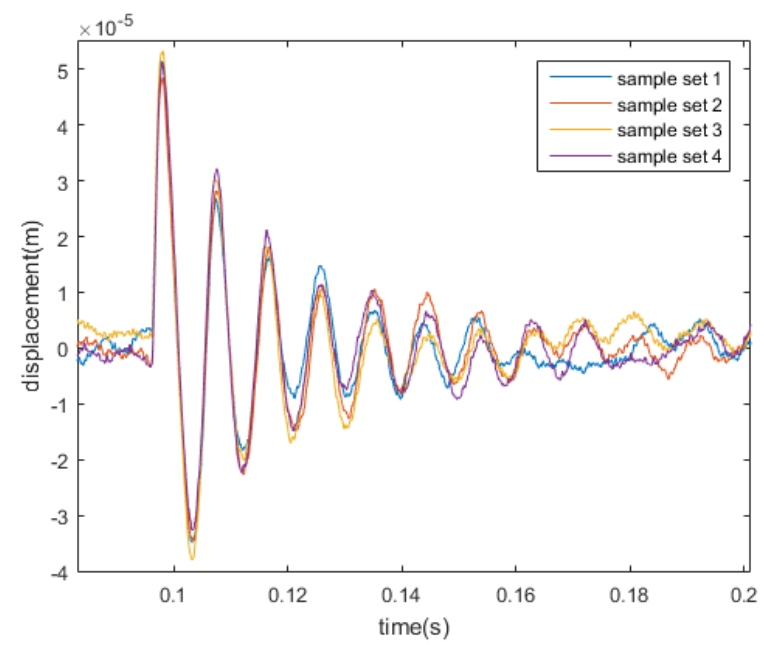

Figure 29. Four sets of averaged relative displacements, calculated at $7.5 \mathrm{krpm}$ and $300 \mathrm{n}$. 
Figure 30 shows the uncertainty range for each $c_{Z}$ value. The error bars reflect two standard deviations. The average standard deviation for $c_{Z}$ is approximately 385 N.s/m. The largest uncertainty for $c_{Z}$, it is at the low-speed, low-load point.

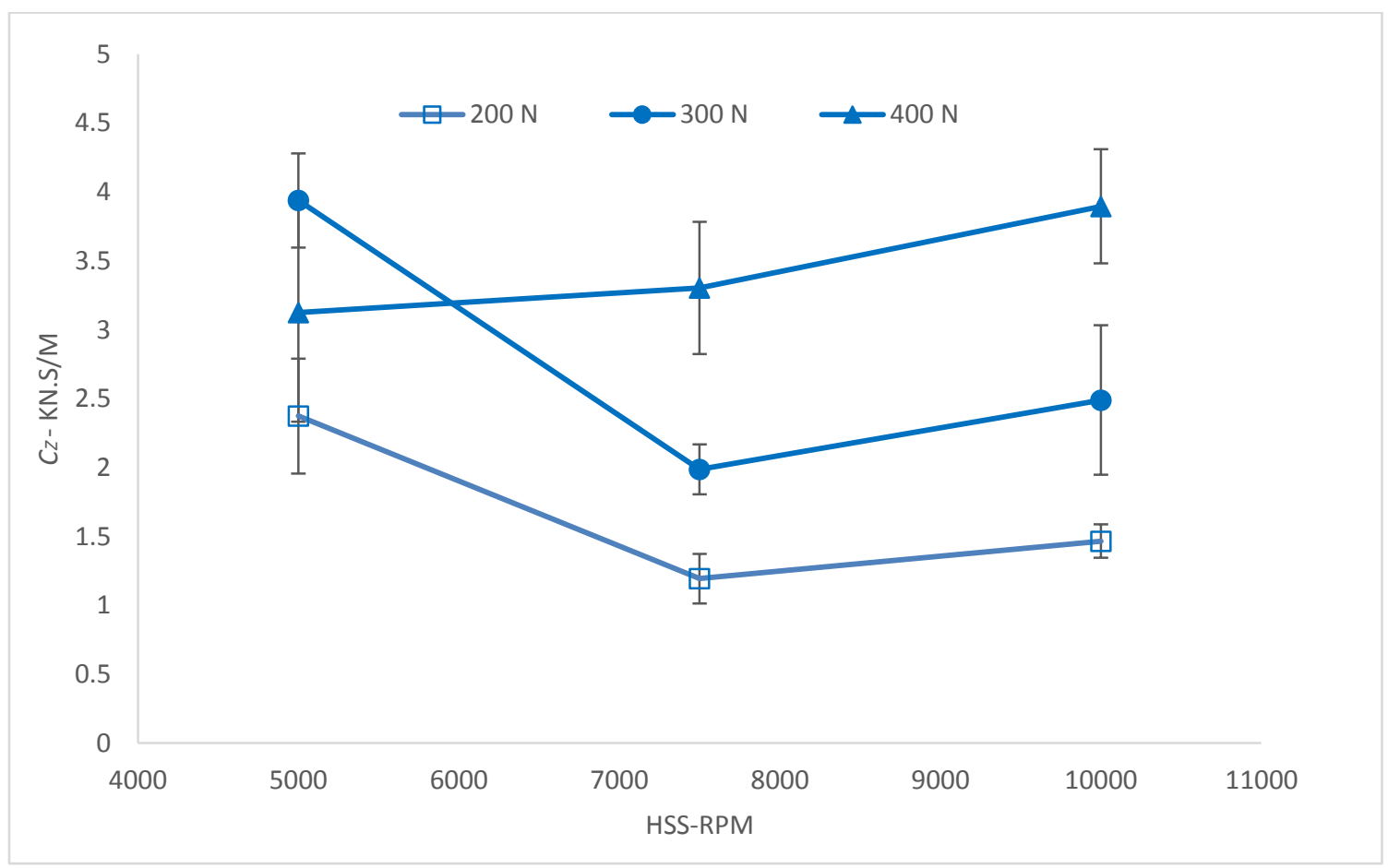

\section{Figure 30. Measured $c_{z}$ versus $\omega$ showing standard deviation.}

Figure 31 presents $m_{z}$ vs. $\omega$ for each $\bar{F}_{z}$. Included in the plot is one standard deviation interval for each data point. The standard deviation range is small for each data point, averaging only $0.6 \mathrm{~kg}$. The uncertainty range is shown through the error bars at each point. The range is larger for $c_{z}$ than for $m_{z}$. For $m_{Z}$ the largest uncertainty is at the $300 \mathrm{~N}, 7.5 \mathrm{krpm}$ test case, and is $0.99 \mathrm{~kg}$. 


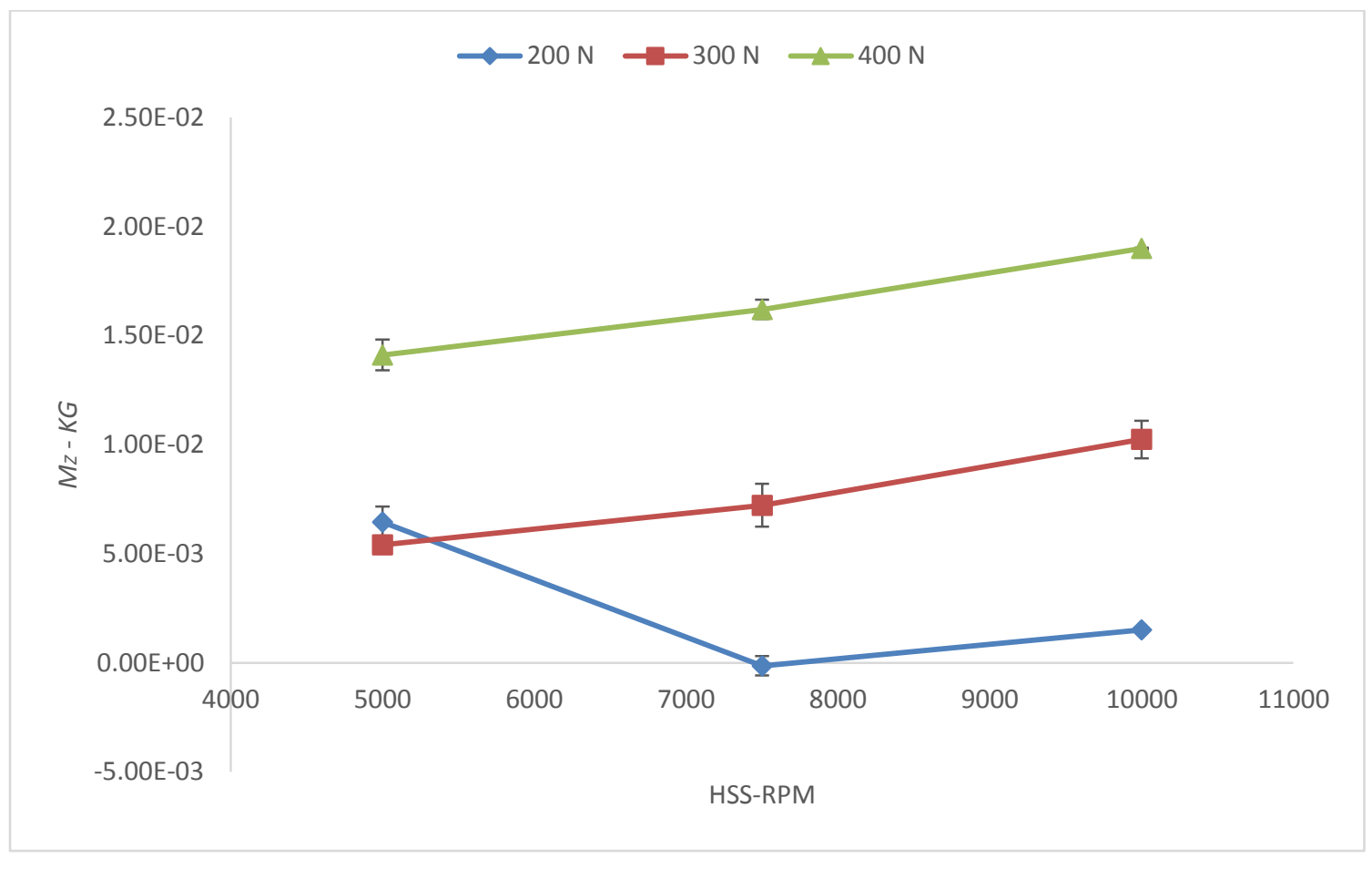

Figure 31. Measured $m_{z}$ versus $\omega$ showing standard deviation. 


\section{SUMMARY AND CONCLUSIONS}

There is scant available literature for the dynamic characteristics of TCs for use in IGCs. There are no published results for measurements of the axial damping $\left(c_{z}\right)$, stiffness $\left(k_{z}\right)$, and virtual-mass $\left(m_{z}\right)$ coefficients. Cable [5] uses a Reynolds equation model and presents the model. The reaction-force model $F_{T C}=-k_{z} \Delta_{z}-c_{z} \dot{\Delta_{z}}$. There are no benchmarked results for comparison to his predictions for $k_{z}$ and $c_{z}$. This project aimed to measure $k_{z}$ and $c_{z}$ for the TC-lubricated area and to compare them to the predictions from Cable.

The TC and BW have a 2 degree taper angle, and the rest of the TC dimensions are comparable of TCs used in IGCs. The author conducts tests at HSS speeds of $\omega=$ $5,7.5$, and $10 \mathrm{krpm}$, LSS speeds of $\omega_{\text {LSS }}=0.43,0.65$, and $0.86 \mathrm{krpm}$ and axial loads of $\bar{F}_{z}=200,300$, and 400 newtons. The lubricant sprayed into the TC is ISO VG 32 oil. Flow is maintained at 19 liters per minute for all test points.

The upstream and downstream temperatures of the lubricant are measured throughout the test. There is a modest $8^{\circ} \mathrm{C}$ rise in temperature for each test point in the test matrix. This increase can be attributed to the friction between the TC and BW and heat input from the pumps. The average temperature is used for the predictive code.

The author performed static tests to determine axial measured stiffness coefficients $\left(\bar{k}_{Z}\right)$. To the authors knowledge this is the first load-deflection test conducted on a TC. The static load is increased and the relative axial displacement of the lubricated area is measured. The slope of the load-displacement function is $\bar{k}_{Z} \cdot \bar{k}_{Z}$ tends 
to increase as both spin speed $(\omega)$ and $\bar{F}_{Z}$ increase. Both predicted and measured $\bar{k}_{Z}$ increase with increasing $\bar{F}_{z}$. Measured $\bar{k}_{Z}$ are close to predictions at $5 \mathrm{krpm}$, but, the code predicts a decrease in $\bar{k}_{Z}$ with increasing $\omega$, while measured $\bar{k}_{Z}$ increases with increasing $\omega$.

The author then performs dynamic tests. An impact hammer excites the system, while displacement probes measure the movement of the TC and the BW near the overlap area of the lubricated zone. Successive peaks are used to calculate the log decrement and damped period of the relative displacement. Stiffness and damping can be calculated from the log dec and damped period.

The measured dynamic stiffness $k_{z}$ values are markedly smaller than the static stiffness coefficients, $\bar{k}_{Z}$. This leads to the conclusion that the model is inadequate. The new model was used incorporating a virtual mass coefficient $\left(m_{z}\right)$. The author used the $\log$ dec, damped period, and static stiffness results to calculate $m_{z}$ and $c_{z} \cdot m_{z}$ increases as a function of $\omega$ and $\bar{F}_{z}$. It ranges from 0 to $19.5 \mathrm{~kg}$; the mass of the pinion shaft is 12.8 $\mathrm{kg}$.

Measured $c_{Z}$ values increase with increases in $\omega$ and $\bar{F}_{z}$. The code predicts significantly higher values for $c_{Z}$ than the measured results; roughly five times higher at $5 \mathrm{krpm}$ and three times higher at $10 \mathrm{krpm}$ for the $400 \mathrm{~N}$ case.

One possible explanation for some of the difference between measurements and predictions is misalignment between the two shafts. A slight misalignment angle could change the cavitated area that would impact the coefficients. When using the code to 
determine predicted $k_{z}$ and $c_{z}$, the author assumes there is no misalignment between the shafts.

Future work on TCs could conduct tests at higher loads. Tests at higher loads would require a more sophisticated model. Other important tests could study the effects of misalignment as compared to industry standard misalignments. The temperature rise of the lubricant and type of lubricant are also important aspects of TCs that have not been thoroughly investigated. 


\section{REFERENCES}

[1] Wygant, K., Bygrave, J., Bosen, W., and Pelton, R., 2016, “Tutorial on the Application and Design of Integrally Geared Compressors," Proceedings of the First Asia Turbomachinery and Pump Symposium, Texas A\&M University, College Station, TX.

[2] Cameron, C. L. R. A. 1975, "Comparison of calculated and measured performace of tiliting pads by means of interferometry," in Studies in Hydrodynamic Thrust Bearings, London, Lubrication Laborotory, imperial college of Science and technology.

[3] Fingerhut, U., Rothstein, E. and Sterz, G., 1991, "Standardized Integrally Geared Turbomachines - Tailor-made for the Process Industry," Proceedings of the Twentieth Turbomachinery Symposium, Texas A\&M University, College Station, TX.

[4] Niederhauser, J., 1925, “Apparatus for Balancing the Axial Thrust in Single Helical Toothed Wheel Gearing," U.S. Patent No. 1,548,545

[5] T. A. Cable, 2015, “Analysis of Oil Lubricated Thrust Collars for Application in Integrally Geared Compressors," M.S. thesis, Dept. Mech. Eng., Texas A\&M Univ., College Station, 2015.

[6] Sadykov, V. A., and Shneerson, L. M., 1968, "Helical Gear Transmissions with Thrust Collars," Russian Engineering Journal, 48(1), pp. 31-34.

[7] Langer, H., 1982, "Hydrodynamische Axialkraftübertragung bei Wellen Schnellaufender Getriebe," Konstruktion, 34(12), pp. 473-478.

[8] Deitz, P. and Mupende, I., 2006, "Pressure ridge - An Old Machine Element with a New Potential Application," Konstruktion, 58, pp. 69-75.

[9] Simon, V., 1984, "Thermal Elastohydrodynamic Lubrication of Rider Rings," ASME J. Trib, 106(4), pp. 492-498.

[10] Yu, T.H. and Sadeghi, F., 2002, "Thermal Effects in Thrust Washer Lubrication," ASME J. Trib., 124, pp. 166-177. 
[11] Barragan, F., Evans, H. P., and Snidle, R. W., 1996, “Thrust Cone Lubrication Part 2: Elastohydrodynamic Analysis of Crowned Rims," IMechE Journal of Engineering Tribology, 210(2), pp. 97-105.

[12] Parkins, D., and Rudd, L., 1996, "Thrust Cone Lubrication Part 3: A Test Facility and Preliminary Measured Data," IMechE Journal of Engineering Tribology, 210(2), pp. 107-112.

[13] Thoden, D., 2006, "Elastohydrodynamische Schmierung von Druchkämmen," 31, pp. 23-26, Technische Universität Clausthal: Institut für Maschinenwesen.

[14] Thoden, D., 2009, "Neuer Prüfstand für Verschleibuntersuchungen an Druchkämmen,” 34, pp. 115-118, Technische Universität Clausthal: Institut für Maschinenwesen.

[15] Hess, M., 2013, “Der Vollschmierung auf der Spur,” 38, pp. 121-138, Technische Universität Clausthal: Institut für Maschinenwesen.

[16] Cable. T.A., San Andrés, L., and Wygant, K., 2016, "On the Predicted Effect of Angular Misalignment on the Performance of Oil Lubricated Thrust Collars in Integrally Geared Compressors," Proceedings of the Sixty-First ASME Turbo Expo, GT2016-57888, Seoul, South Korea, pp. 1-13.

[17] Childs, D.W., and Phillips, S.G., 2012, "Measuring Stiffness and Damping Coefficients for Thrust Collars for Samsung-Techwin," TEES Project Proposal No. 1214764, Texas Engineering Experiment Station, College Station, TX. 


\section{APPENDIX A}

\section{TABULATED RESULTS}

Table A.1. All stiffness and damping values for measured results along with standard deviation.

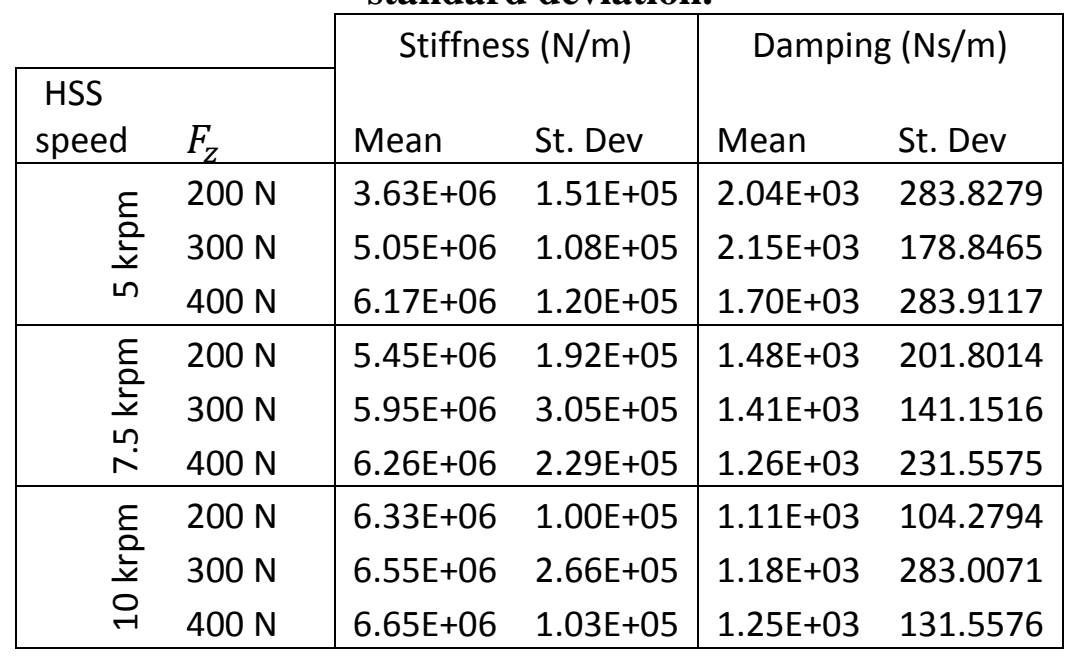

Table A.2. Static and dynamic stiffness values calculating virtual mass

\begin{tabular}{l|ccc|ccc|ccc|}
\cline { 2 - 9 } & \multicolumn{3}{|c|}{$5 \mathrm{krpm}$} & \multicolumn{3}{c|}{$7.5 \mathrm{krpm}$} & \multicolumn{3}{c|}{$10 \mathrm{krpm}$} \\
$k_{z}$ & 200 & & \multicolumn{3}{c|}{300} & & \\
$\bar{k}_{z}$ & $\mathrm{~N}$ & $300 \mathrm{~N}$ & $400 \mathrm{~N}$ & $200 \mathrm{~N}$ & $\mathrm{~N}$ & $400 \mathrm{~N}$ & $200 \mathrm{~N}$ & $300 \mathrm{~N}$ & $400 \mathrm{~N}$ \\
\cline { 2 - 10 } & 3.2 & 5.5 & 5.8 & 5.5 & 5.6 & 5.8 & 6.1 & 6.1 & 6.6 \\
& 4.9 & 7.9 & 11.4 & 5.4 & 8.8 & 13.1 & 6.8 & 11.0 & 16.6 \\
$\mathrm{wd}$ & 499 & 648 & 671 & 651 & 659 & 669 & 687 & 689 & 715 \\
$\mathrm{mz}$ & 6.5 & 5.5 & 12.4 & -0.1 & 7.2 & 16.3 & 1.52 & 10.3 & 19.5
\end{tabular}


Table A.3. Log Dec Number

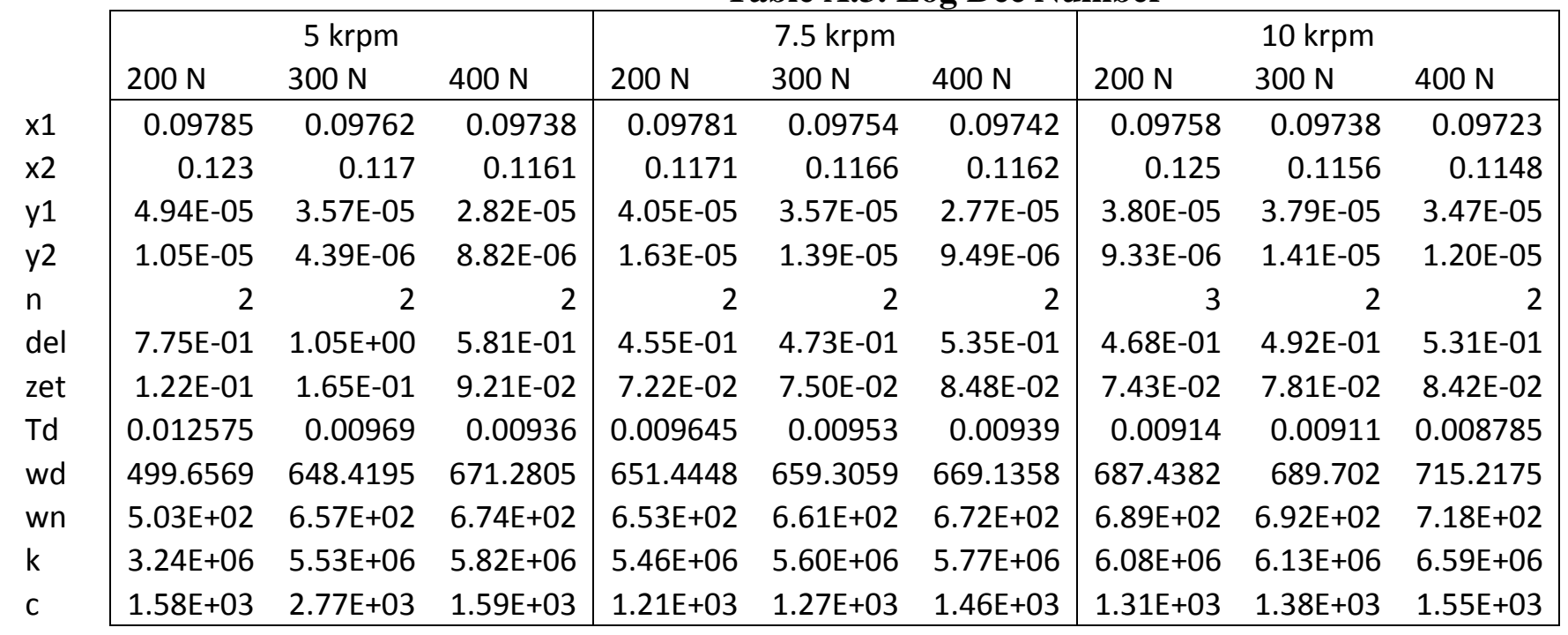

